\title{
Vertical structure and radiative forcing of monsoon clouds over Kanpur during the 2016 INCOMPASS field campaign
}

Article

George, G., Sarangi, C., Tripathi, S. N., Chakraborty, T. and Turner, A. (2018) Vertical structure and radiative forcing of monsoon clouds over Kanpur during the 2016 INCOMPASS field campaign. Journal of Geophysical Research:

Atmospheres, 123 (4). pp. 2152-2174. ISSN 2169-8996 doi: https://doi.org/10.1002/2017JD027759 Available at https://centaur.reading.ac.uk/73942/

It is advisable to refer to the publisher's version if you intend to cite from the work. See Guidance on citing.

To link to this article DOI: http://dx.doi.org/10.1002/2017JD027759

Publisher: American Geophysical Union

All outputs in CentAUR are protected by Intellectual Property Rights law, including copyright law. Copyright and IPR is retained by the creators or other copyright holders. Terms and conditions for use of this material are defined in the End User Agreement. 


\section{CentAUR}

Central Archive at the University of Reading

Reading's research outputs online 


\section{Journal of Geophysical Research: Atmospheres}

\section{RESEARCH ARTICLE \\ 10.1002/2017JD027759 \\ Key Points: \\ - First-of-its-kind study from India \\ Vertical Structure and Radiative Forcing of Monsoon Clouds Over Kanpur During the 2016 INCOMPASS Field Campaign} shows cloud structure to be multilayered during Indian monsoon

- Significant changes were found in cloud structure and forcing during depression periods

- Cloud structure parameters are strongly associated with forcing at surface and top of atmosphere

Correspondence to:

S. N. Tripathi,

snt@iitk.ac.in

\section{Citation:}

George, G., Sarangi, C., Tripathi, S. N., Chakraborty, T., \& Turner, A. (2018). Vertical structure and radiative forcing of monsoon clouds over Kanpur during the 2016 INCOMPASS field campaign. Journal of Geophysical Research: Atmospheres, 123. https://doi.org/10.1002/2017JD027759

Received 21 SEP 2017

Accepted 14 JAN 2018

Accepted article online 18 JAN 2018

\author{
Geet George ${ }^{1}\left(\mathbb{D}\right.$, Chandan Sarangi ${ }^{2,3} \mathbb{D}$, Sachchida Nand Tripathi ${ }^{2,4}(\mathbb{D}$, \\ Tirthankar Chakraborty ${ }^{4,5}$ iD, and Andrew Turner ${ }^{6,7}$
} Centre for Atmospheric Science, University of Reading, Reading, UK
${ }^{1}$ Environmental Engineering and Management Programme, IIT Kanpur, Kanpur, India, ${ }^{2}$ Department of Civil Engineering, IIT Kanpur, Kanpur, India, ${ }^{3}$ Atmospheric Sciences and Global Change, Pacific Northwest National Laboratory, Richland, WA, USA, ${ }^{4}$ Centre for Environmental Science and Engineering, IIT Kanpur, Kanpur, India, ${ }^{5}$ School of Forestry and Environmental Studies, Yale University, New Haven, CT, USA, ${ }^{6}$ Department of Meteorology, University of Reading, Reading, UK, ${ }^{7}$ National

Abstract An overview of cloud vertical structure (CVS) and cloud radiative forcing (CRF) during Indian summer monsoon is obtained over Kanpur, through observations made during the Interaction of Convective Organisation and Monsoon Precipitation, Atmosphere, Surface and Sea field campaign of 2016. Associations of CVS parameters with CRF at surface and top of atmosphere (TOA) are also investigated. One hundred thirty-seven radiosondes were launched at Indian Institute of Technology Kanpur, between 5 and 28 July 2016. CVS is determined using an algorithm that identifies cloud layers from vertical profiles of relative humidity, with altitude-dependent relative humidity thresholds. CVS is analyzed by separating the campaign period on the basis of presence and absence of depressions/low-pressure systems. Compared to nondepression periods, low-pressure events showed significant difference in all CVS and CRF parameters except cloud top height. CVS was multilayered in $\sim 75 \%$ launches, with deep, mixed-phase clouds being present in $\sim 70 \%$ launches. CRF was calculated from clear-sky measurements and TOA observations from Clouds and the Earth's Radiant Energy System satellite retrievals, and surface measurements. A net cooling effect was found overall, with instantaneous shortwave CRF (mean values of -95.92 and $-101.89 \mathrm{~W} / \mathrm{m}^{2}$ at surface and TOA, respectively) dominating longwave cloud radiative forcing (LWCRF) (mean values of 15.33 and $66.55 \mathrm{~W} / \mathrm{m}^{2}$ at surface and TOA, respectively). Results suggest that shortwave CRF depends on total depth of cloud layers and is independent of cloud altitude, whereas LWCRF depends on both depth and vertical location of cloud layers, with base and top heights regulating LWCRF at surface and TOA, respectively.

Plain Language Summary Cloud vertical structure (CVS) and cloud radiative forcing (CRF) are important parameters in our understanding of clouds and climate prediction. CVS includes details about number of cloud layers present in the atmosphere and the base and top height of these layers. CRF is the extent of change caused in Earth's energy balance due to the presence of clouds. This study is the first of its kind from India, which provides information regarding CVS during the Indian monsoon, by using data from weather balloons. The results of the study show that most of the time, there are multiple layers of clouds present and that most are deep clouds. Indian monsoons are characterized by large-scale events called depressions, when the pressure of air over land drops. Periods with such low-pressure events showed a significant difference in all CVS details except cloud top height, when compared to nondepression periods. CRF values were calculated, and an overview of CRF during Indian summer monsoon is presented. It is also observed that the parameters of CVS had a range of significant influences on CRF. The results of this study can be used as information to be provided to models, which will help in the understanding of monsoons.

\section{Introduction}

Clouds play a significant role in regulating the climate, the global-scale hydrological cycle, and the general circulation of the atmosphere (G. E. Hunt, 1980; Ramanathan et al., 1989; Stephens, 2005). Over the years, numerous studies have consistently stressed the importance of understanding clouds, because of their role
O2018. American Geophysical Union. All Rights Reserved. 
in influencing the efficiency of our global as well as regional models (Liang \& Wang, 1997; Slingo \& Slingo, 1988; Zhang et al., 2014).

Stephens (1978), with the help of theoretical computational models including multiple scattering, explained the dependence of cloud radiative forcing (CRF) on cloud macrostructure. He underlined the importance of factors such as the vertical location of clouds in the atmosphere and their type. However, the significance of cloud vertical structure (CVS) specifically, in modeling the atmospheric circulation in a general circulation model, was brought out by J. Wang (1998). Both these studies maintained that theoretical model experiments targeted at understanding the relation between clouds, their forcing, and the atmospheric circulation, should be verified and backed up by means of observational evidence, in order to properly understand the interaction between clouds and radiation. Studies such as W. C. Wang (2004) and Saud et al. (2016) have emphasized the importance of understanding CVS, in order to gain more understanding of CRF. Saud et al. (2016) specifically suggest that CVS should be resolved as a multilayer field wherever possible, for a better picture of the dependence of CRF on CVS. Hence, it is important that there is considerable clarity regarding our understanding of CVS.

Surface-based and satellite observations are efficient in the detection of cloud bases and tops, respectively; however, deep clouds and high optical thickness often prevent observation of the entire vertical profile, due to "obscuration" (Zhang et al., 2014). Hence, such observations miss important factors such as the presence of multiple layers and the thickness of cloud-free air masses between cloud layers. While there are highly efficient lidars and radars available that manage to profile cloud layers from the surface, an effective method to obtain a complete CVS is by in situ means, such as weather balloons/radiosondes. Several studies have profiled the vertical structure of clouds by means of the measurements from radiosondes/rawinsondes, on global scales as well as locally (J. Wang, 1999, 2000; Poore et al., 1995; Zhang et al., 2010, 2014).

Clouds reflect incoming shortwave (SW) radiation (albedo effect) and absorb (and re-emit) outgoing longwave (LW) radiation, causing a cooling and warming effect, respectively. The net magnitude of this perturbation in radiative balance at surface and at top of atmosphere (TOA), due to clouds, is measured in terms of CRF. Henceforth, in this study, the prefixes "SW," "LW," and "net" for CRF stand for shortwave, longwave, and net CRF, respectively. The subscripts "srf" and "toa" stand for forcing at the surface and TOA, respectively.

To validate the theoretical studies on radiative balance perturbation due to clouds, there were numerous studies conducted on measuring the net $\mathrm{CRF}_{\text {toa }}$ (detailed summary provided by Hartmann et al., 1986). However, there are very few studies that have determined CRF at the surface. As highlighted by Stephens (2005), the need for understanding $\mathrm{CRF}_{\text {srf }}$ is important because of its influence on the surface energy balance, viz., changes in latent heat, sensible heat, and ground heat fluxes, thus causing the boundary layer thermodynamics to change. Thus, the knowledge of CRF at the surface is as important as that at TOA for our understanding of how clouds regulate the Earth's radiative balance.

Studies such as that of Stephens and Webster (1979) and Stephens and Webster (1984) have theoretically investigated the impact of cloud structure on SW and LW radiation. The latter study decoupled the impact that CVS has on $\mathrm{CRF}_{\text {srf }}$ and $\mathrm{CRF}_{\text {toa }}$, using a simple one-dimensional radiative-convective equilibrium model. The different interactions of clouds with SW and LW radiation make the net CRF dependent on various factors. It is quite well known that macrophysical properties of clouds influence CRF. Some intuitive expectations are that cloud base and top heights would regulate the LW forcing by affecting the temperature at which radiation is being absorbed and emitted. Similarly, the cloud depth would affect the optical thickness and thus amount of SW radiation scattered as well as LW radiation absorbed.

The Indo-Gangetic Plain (IGP) is one of the largest river basins in the world in terms of population, with 40\% of India's population dependent on it (N. G. Patil, 2014), and is considered an important study area in terms of environment and climate. The Indian summer monsoon (ISM) influences agriculture and other economic activities in a significant manner for this basin, which in turn, influences the economy of the entire country. The most important synoptic-scale characteristic of the ISM, pertinent to the IGP region is the development of monsoon depressions and weaker low-pressure systems (LPS), which usually originate in the Bay of Bengal, before propagating northwestwards over the landmass (Sikka, 1977). Studies like K. M. Hunt and Parker (2016), K. M. Hunt, Turner, Inness, et al. (2016), and Hurley and Boos (2015) have characterized the dynamics and structure of such depressions. K. M. Hunt, Turner, Inness, et al. (2016) analyzed the vertical structure of clouds during monsoon depressions, using cloud water content from reanalysis data, as a proxy for the type of clouds. 
However, no studies using direct observations are available that delineate the characteristics of cloud structure during monsoon depressions. Although Rajeevan et al. (2013) provide a characterization of the vertical structure of cloud optical properties using CloudSat data, such studies from satellite measurements provide only a broad idea of spatial variation in CVS. No studies have been performed over the IGP region that determine the CVS by means of in situ measurements such as radiosondes, which are able to provide a highfrequency and detailed data set. The present study involves temporally dense data points from radiosonde launches, over the IGP within a short, core monsoonal timespan; the study is thus able to focus on the short time scale processes that may be occurring in CVS over individual synoptic events. Such observations regarding macrophysical properties of clouds, especially during monsoon depressions and smaller LPS, can help cloud-resolving models in more accurate simulations, and studies such as that by K. M. Hunt (2017) (modeling study), Sarangi et al. (2015) (modeling study combined with aircraft measurements and satellite data), and K. M. Hunt, Turner, and Parker (2016) (modeling study combined with satellite data) can be supplemented with information that would help provide a fuller picture of exactly how the ISM behaves during a depression period. Moreover, information regarding the presence of multilayer cloud structure can benefit studies related to aerosol-cloud interaction during ISM such as Sarangi et al. (2017), which usually assume a single-layer cloud structure.

Studies by Saud et al. (2016) and Ravi Kiran et al. (2015) have studied the CRF at TOA over the Indian subcontinent, and associated it with various cloud parameters such as cloud cover, cloud optical depth (COD), and cloud top pressure as well as cloud liquid and ice water path. The present study analyses the CRF with the collocated cloud pattern observed during the same time. The objective of these analyses is to investigate how CVS (base height, top height, and cloud depth) can affect the CRF at the surface and at TOA. Thus, this study, along with calculating the magnitude of $\mathrm{CRF}_{\text {sff }}$ and $\mathrm{CRF}_{\text {toa }}$, also associates the values of CRF with concurrent parameters of CVS obtained, in order to obtain a more comprehensive understanding of how the monsoonal cloud system influences CRF.

The present study was carried out as a part of the Interaction of Convective Organisation and Monsoon Precipitation, Atmosphere, Surface and Sea (INCOMPASS) project (see Turner et al., 2017, for details). The primary objectives of this study are the following: (1) To characterize the CVS over Kanpur for the depression and nondepression periods during the 2016 ISM; (2) to quantify the associated SW, LW, and net CRF at the surface as well as TOA; and (3) to examine the association between CVS and CRF.

The methodology and instrumentation is explained in section 2. The CVS and CRF results are shown in sections 3 and 4, respectively. Associations between CVS and CRF are investigated in section 5.

\section{Methodology}

\subsection{Instruments and Measurements}

As part of the INCOMPASS project, a radiosonde (RS) campaign was executed at Indian Institute of Technology Kanpur (IITK; $26.519^{\circ} \mathrm{N}, 80.233^{\circ} \mathrm{E}$ and $\sim 126 \mathrm{~m}$ above mean sea level), which is a semiurban area on the outskirts of Kanpur City, situated in central IGP. The weather at Kanpur is dominated by the monsoon system during the months from mid-June to mid-October, with the prevailing winds being predominantly easterly. The radiosondes were launched from the institute's airstrip, a sufficiently wide open area, to ensure minimal surface interference in the balloon's natural course of flight. The radiosonde launch site has been marked in Figure 1. Vaisala radiosondes RS41 were used for the campaign, which include humidity and temperature sensors along with a Global Positioning System receiver (see Jensen et al., 2015, for details regarding performance of radiosonde Vaisala RS41). Thus, entire vertical profiles with measurements of relative humidity (RH), temperature, wind speed, wind direction, and altitude were obtained at a temporal resolution of $1 \mathrm{~s}$. There were a total of 137 launches carried out, without any major interruption, between 5 and 28 July 2016. Overall, a frequency of one launch every $4 \mathrm{~h}$ was maintained during the campaign period.

For identifying passing depressions or LPS during the campaign period, reanalysis data from ERA-Interim by the European Centre for Medium-Range Weather Forecasts was used (Dee et al., 2011). Relative vorticity (RV) and wind vectors were obtained at a horizontal resolution of $1^{\circ} \times 1^{\circ}$ at a pressure level of $850 \mathrm{hPa}$, for the campaign period at daily times of 00:00, 06:00, 12:00, and 18:00 Universal Coordinated Time (UTC).

A Campbell Scientific ceilometer, CS135, is installed on the roof of the control tower at the airstrip in IITK (same site as radiosonde launch site), which measures cloud base height (CBH) every $20 \mathrm{~s}$. The ceilometer has been used to obtain optimum threshold values from Zhang et al.'s (2010) algorithm, such that there is maximum 


\section{AGU Journal of Geophysical Research: Atmospheres}
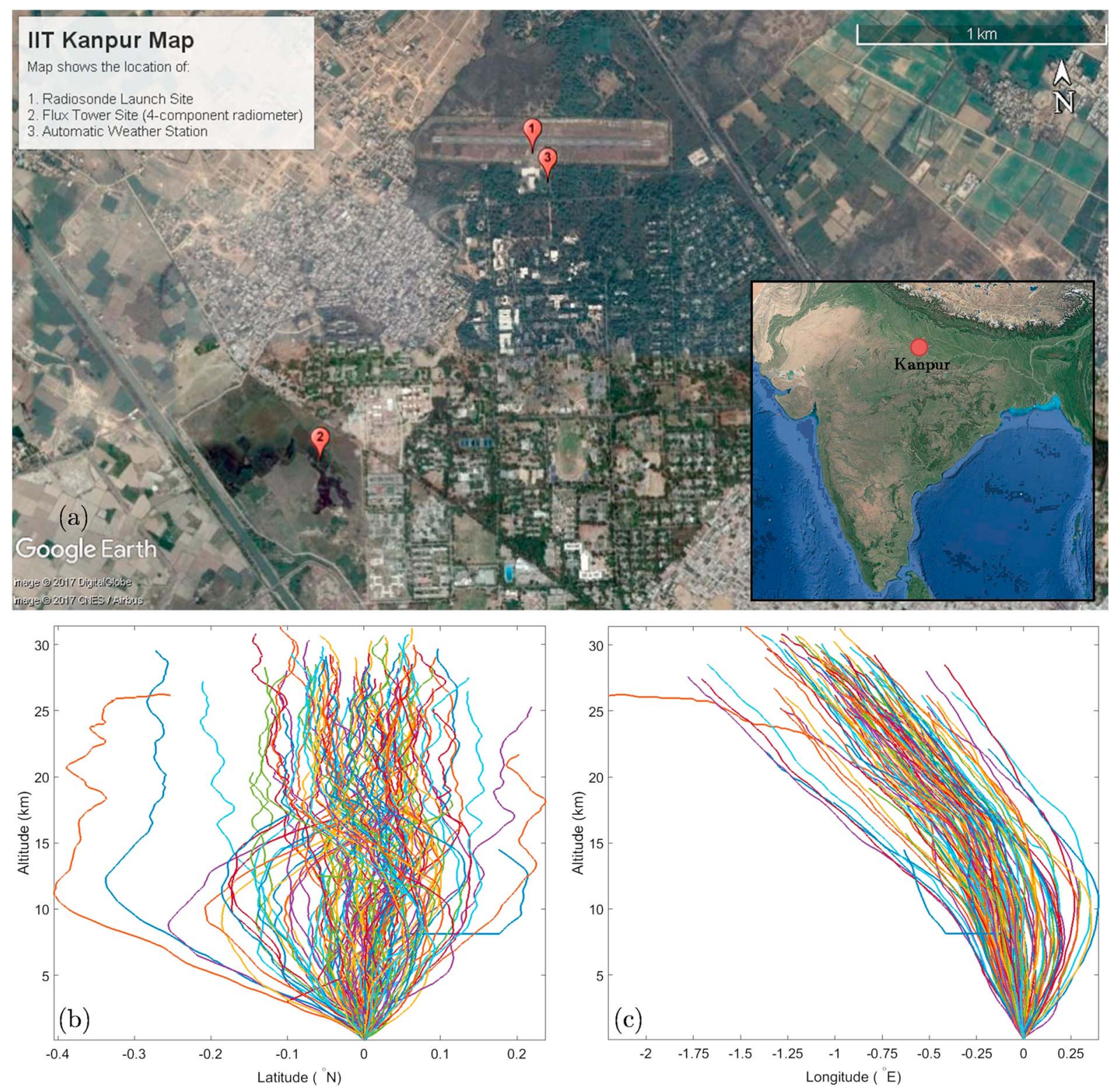

Figure 1. (a) Map of IIT Kanpur marking the locations of (1) Radiosonde Launch Site, (2) Flux Tower, and (3) Automatic Weather Station. The scale of the map and the compass direction have been shown on the top right, and inset image shows location of Kanpur within the Central IGP, in the Indian subcontinent (Image Courtesy: Google Earth); Representation of the drifts in (b) latitude and (c) longitude for each balloon launch with altitude. The coordinates for the launch site $\left(26.519^{\circ} \mathrm{N}, 80.233^{\circ} \mathrm{E}\right)$ correspond to $0^{\circ}$ on the $X$ axis, in Figures $1 \mathrm{~b}$ and $1 \mathrm{c}$.

agreement between the $\mathrm{CBH}$ observations from the ceilometer and the $\mathrm{CBH}$ s detected from the radiosonde soundings. Moreover, an NR-01 four-component radiometer has been set up on a flux tower, in a nearby field ( $1 \mathrm{~km}$ from the radiosonde launch site) at a height of $4.7 \mathrm{~m}$ above ground level (marked as " 2 " in Figure 1). Since the field is a seminatural grassland, it could be considered as representative of the grasslands in the IGP. For this study, the observed data of incoming and outgoing LW and SW radiation at the surface have been obtained from the measurements of this radiometer. Moreover, an automatic weather station (AWS) is also located at the airstrip (marked as " 3 " in Figure 1), which provides weather-related data at 15 min intervals. The measurements available from the station are the near-surface air temperature ( $2 \mathrm{~m}$ altitude), accumulated rainfall every $15 \mathrm{~min}(\mathrm{~mm})$, wind speed $(\mathrm{m} / \mathrm{s})$, wind direction, and the $\mathrm{RH}$, with wind and $\mathrm{RH}$ measurements at $2 \mathrm{~m}$ from the ground. An iNGEN tipping bucket rain gauge (part of the AWS ensemble, colocated with the RS launch site), constructed from thermoplastic base and receiver funnel has been used for precipitation measurements during the study period. 

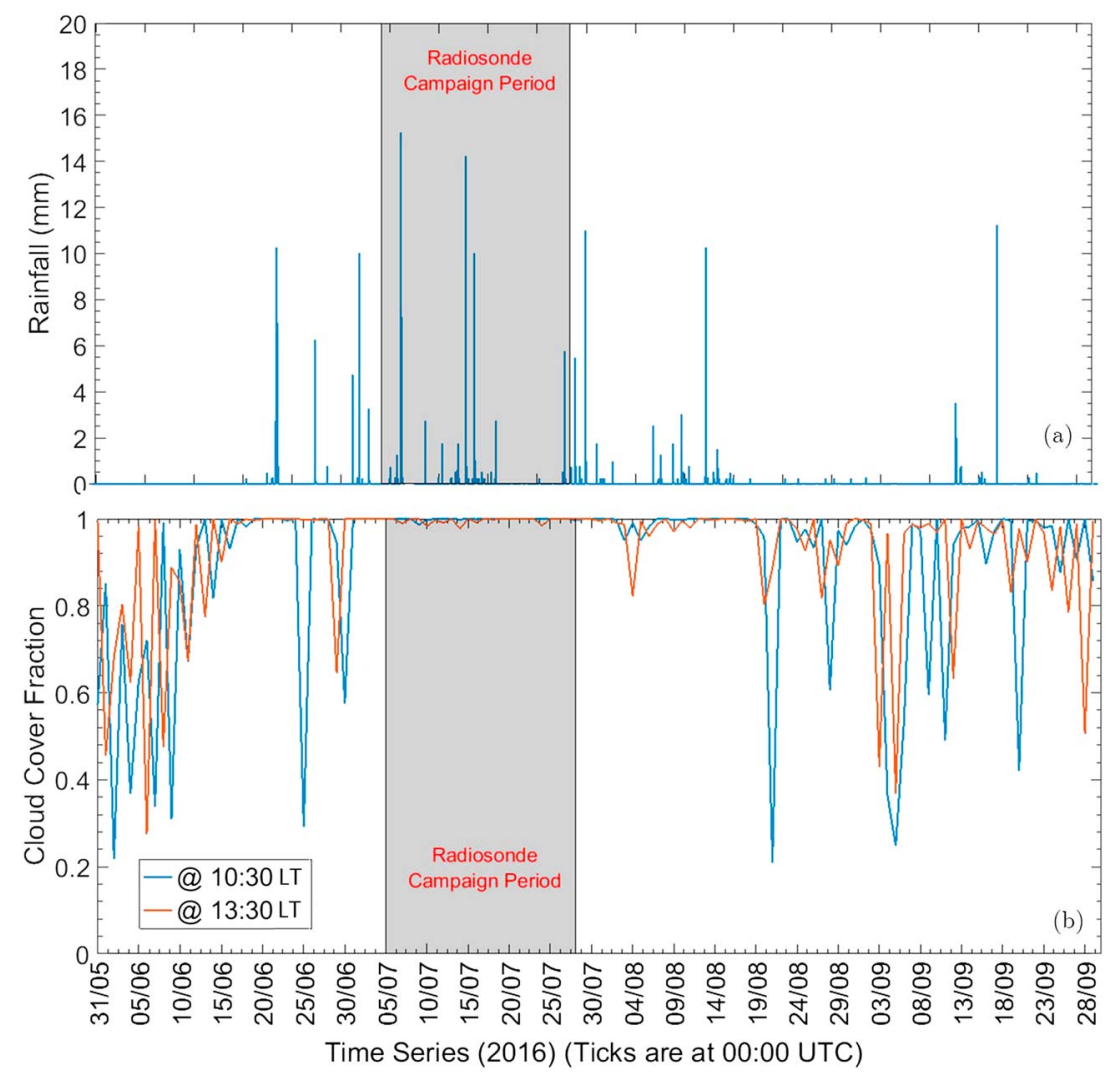

Figure 2. (a) Rainfall (in mm) observed from June through September (JJAS) 2016; measurements taken every 15 min from the AWS installed at IITK. (b) Cloud cover fraction during JJAS 2016 (values taken from measurements by MODIS). Blue and red lines show the values taken when the satellite passes over the local site at 10:30 and 13:30 local time (LT), respectively. The period of the radiosonde campaign has been highlighted with grey shading in both figures.

For the purpose of acquiring clear-sky radiation values as well as TOA values of outgoing LW and SW radiation, data from the Clouds and Earth Radiance Energy System (CERES) was used. CERES is a part of the National Aeronautics and Space Administration's long-term project for global observations, called the Earth Observing System (Wielicki et al., 1996). The product SYN1 deg-3Hour Ed3A of CERES was used to obtain Level 3, observed TOA radiation data averaged every $3 \mathrm{~h}$, at a spatial resolution of $1^{\circ} \times 1^{\circ}$. Other than the observed radiation measurements at TOA, CERES also provides clear-sky radiation values via its Single Scanner Footprint algorithm, wherein it determines clear-sky scenarios based on a 99\% clearance within its footprint of $20 \mathrm{~km}$ nominal resolution. (Clear-sky radiation values are the values of incoming and outgoing SW and LW radiation, under cloud-free conditions.) These clear-sky values were also obtained every $3 \mathrm{~h}$.

\subsection{Regional Scale Meteorology}

Generally, the months from June through September (JJAS) are considered to be the months when the ISM is active. Figure 2a shows the precipitation that occurred over the site during JJAS 2016. According to reports by Indian Meteorological Department, the entire country received an average monsoon ( $97 \%$ of its long-period average rainfall) in JJAS 2016, while the region in which Kanpur lies, east Uttar Pradesh, received 12\% lower rainfall than average, which also falls within the normal range (http://imd.gov.in/pages/monsoon_main/). The normal onset and withdrawal dates for the eastern Uttar Pradesh region (where Kanpur is situated) are between 15 June and 1 July and between 15 September and 1 October, respectively. For 2016, the observed onset and withdrawal dates were in the range of 22-25 June and 12-13 October, respectively, and the IITK rain gauge data agrees well with these dates (Figure $2 a$ ).

Figure 2a shows that the period of the RS campaign encompassed the two heaviest instances of rainfall of the season. Maximum daily rainfall for the entire season observed was close to $30 \mathrm{~mm}$ (15 July) at Kanpur, while the average daily rainfall for July came to around $5.5 \mathrm{~mm}$, including the nonrainy days. 


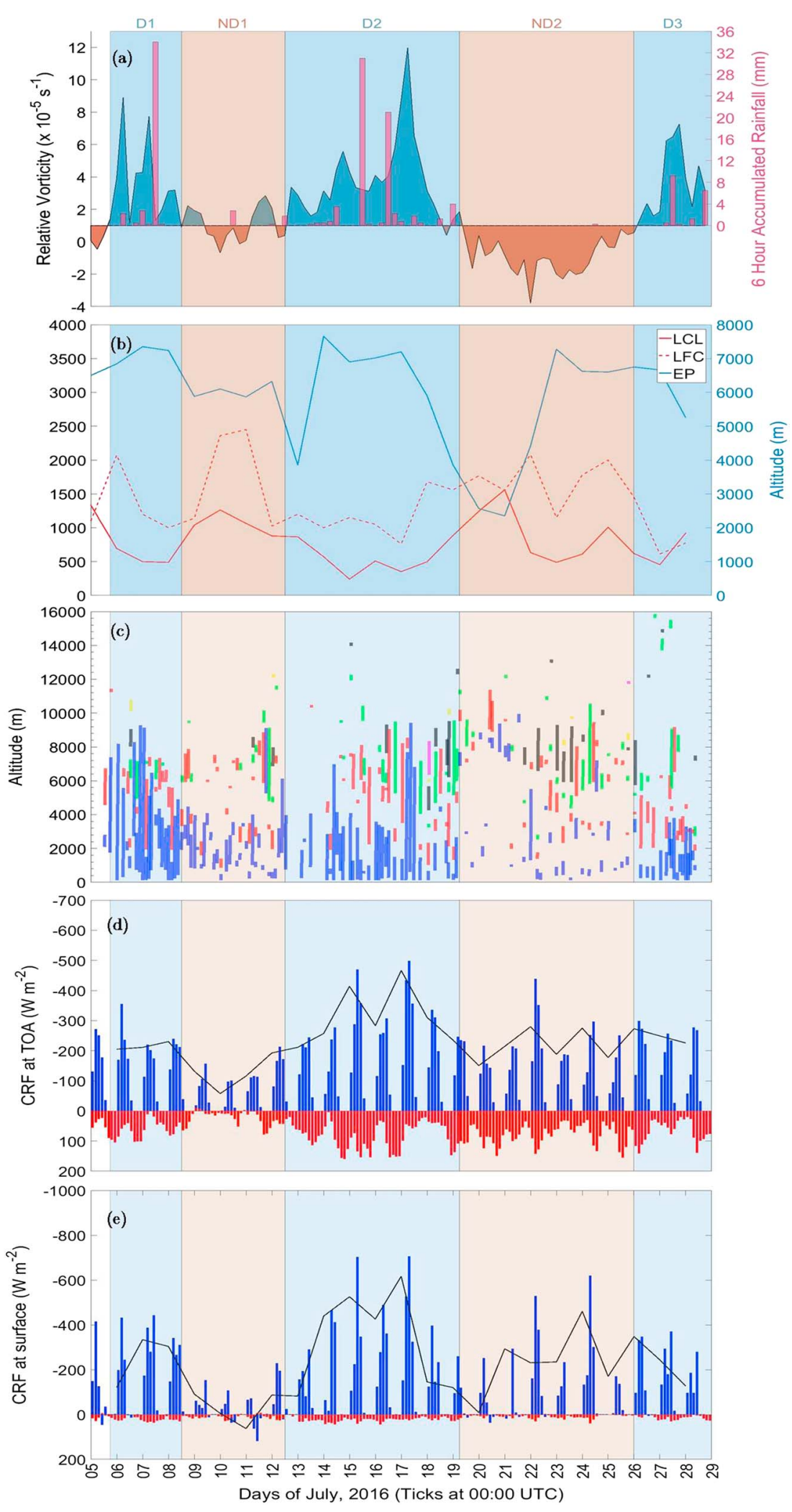

Figure 3. Timeline of (a) RV (left $Y$ axis, plot line) and $6 \mathrm{~h}$ rainfall (right $Y$ axis, bars); (b) daily mean values of LCL, LFC (left $Y$ axis, red), and EP (right $Y$ axis, blue); (c) entire CVS showing location of all layers; and (d and e) $\mathrm{CRF}_{\text {toa }} \& \mathrm{CRF}_{\text {srf }}$. The $D$ and ND phases are highlighted in blue and red background, respectively. In Figure 3a, blue and red areas show $\mathrm{RV}$ values above and below trivial threshold values, respectively. Black plotlines in Figures $3 \mathrm{~d}$ and $3 \mathrm{e}$ show daily mean values for SWCRF at the surface and TOA, respectively. 
Table 1

Table Provides Details of the Various Phases Into Which the Radiosonde Campaign Has Been Separated, Along With Their Associated Parameter Values

\begin{tabular}{|c|c|c|c|c|c|}
\hline Phase & $\begin{array}{l}\text { Duration } \\
\text { (July 2016) }\end{array}$ & $\mathrm{RV}$ at $850 \mathrm{hPa}\left(\times 10^{-5} \mathrm{~s}^{-1}\right)$ & $\begin{array}{l}\text { Wind speed } \\
\text { at } 850 \mathrm{hPa}(\mathrm{m} / \mathrm{s})\end{array}$ & Daily rainfall (mm) & $\begin{array}{l}\text { Site with respect to } \\
\text { core of depression }\end{array}$ \\
\hline D1 & $5(18: 00)$ to $8(12: 00)$ & $3.74( \pm 2.43)$ & $8.43( \pm 2.13)$ & $13.33( \pm 15.13)$ & Northwest \\
\hline ND1 & $8(12: 00)$ to $12(12: 00)$ & $1.08( \pm 1.01)$ & $7.63( \pm 1.86)$ & $1.18( \pm 1.12)$ & N/A \\
\hline D2 & $12(12: 00)$ to $19(06: 00)$ & $3.71( \pm 2.44)$ & $4.80( \pm 3.61)$ & $9.82( \pm 11.69)$ & Within \\
\hline ND2 & $19(06: 00)$ to $26(00: 00)$ & $-0.90( \pm 1.15)$ & $3.98( \pm 2.78)$ & $0.04( \pm 0.09)$ & $\mathrm{N} / \mathrm{A}$ \\
\hline D3 & $26(00: 00)$ to $29(00: 00)$ & $3.48( \pm 2.13)$ & $5.25( \pm 1.72)$ & $7.17( \pm 5.10)$ & $\begin{array}{c}\text { Shifted from NW to } \\
\text { within core to SE }\end{array}$ \\
\hline
\end{tabular}

Note. All parameter values are mean values, and those within parentheses denote the normalized standard deviation for the respective parameters. "N/A," "NW," and "SE" stand for "not applicable," "northwest," and "southeast," respectively.

Moreover, as seen in Figure 2b, the pattern of cloud fraction (determined from satellites Moderate Resolution Imaging Spectroradiometer (MODIS): Terra and Aqua) remained quite erratic during the onset and withdrawal stages. However, during the core months (i.e., July-August), it remained steady at over 0.8 , while for the entire radiosonde campaign, the cover fraction never fell below 0.95 ; thus, we can safely assume it to be a fairly nonvarying parameter in this instance. Thus, the INCOMPASS Kanpur RS campaign was able to capture the period with maximum rainfall and cloud fraction, representing near-perfect monsoonal conditions for the experiment to study clouds during ISM 2016.

To distinguish between the periods with depressions or LPS and those without, the RV values over the site were analyzed as in Figure 3a. A trivial threshold value of $10^{-5} \mathrm{~s}^{-1}$ (shown as baseline value in Figure 3a) was set in order to identify a depression period, as part of the methodology implemented by K. M. Hunt, Turner, Inness, et al. (2016). A depression or LPS is confirmed only if the threshold value is exceeded constantly for a period of more than $24 \mathrm{~h}$. Moreover, the direction of wind vectors were used as a means of visual confirmation. On this basis, the campaign period has been divided into depression (D) and nondepression (ND) phases, as shown in Table 1.

As per an analysis of cyclone life cycle in relation to maximum RV at a pressure level of $850 \mathrm{hPa}$ by Dacre et al. (2012), the events D1 and D3 of the observing period can be termed as decaying and developing depression periods, respectively. In the same light, phase D2 can be said to be a complete life cycle development of a depression period. Moreover, the location of the site (Kanpur) with respect to the core of the depression (identified visually) also differed for the three D phases. For D1, Kanpur was downwind of the core, while for D2, Kanpur was in close proximity to the core, although slightly leaning downwind. For D3, Kanpur was initially downwind but was then gradually engulfed by the core, and then as the trough progressed further, Kanpur was on the upwind side. Studies such as those by Barnes et al. (1983) and Hence and Houze (2008) have observed that the cloud structures present on the downwind and upwind regions of cyclones are stratiform and convective, respectively. This could explain the significantly higher amount of rainfall observed during D1, compared to D2 and D3.

\subsection{Analysis of Radiosonde Launches}

Almost all of the radiosonde launches crossed the tropopause ( $\sim 90 \%)$, with the maximum achieved altitude reaching $31.42 \mathrm{~km}$, nearly double the height of the troposphere. The mean highest altitude achieved by all launches was $\sim 24.5 \mathrm{~km}$. The drift in the path of balloons due to the course of winds is also a crucial aspect when considering observations from radiosonde soundings. As the cloud fraction from $1^{\circ}$-resolved MODIS data set is always $>0.95$ over Kanpur for the RS campaign period (see Figure $2 \mathrm{~b}$ ), it can be assumed that the radiosondes are observing properties of similar cloud systems nearby Kanpur. The mean maximum drift of all launches was $\sim 100 \mathrm{~km}$ from the site, while the maximum and minimum drifts observed were $\sim 238 \mathrm{~km}$ and $\sim 24 \mathrm{~km}$, respectively. These drift statistics are for the maximum values of drift from site achieved during the course of the launch and may not necessarily be the final sounding of the radiosonde. Also, it is important to note here that such high drift values are mainly because of the heavy winds blowing above $\sim 15 \mathrm{~km}$ from the surface as part of the tropical easterly jet (TEJ) present over India during monsoon season, and the maximum drifts usually did not go beyond $\sim 50 \mathrm{~km}$ below this altitude. Figure 1, with respect to latitude (b) and longitude (c), represents the altitudes achieved and drifts experienced by all launches. The figure clearly shows the 
Table 2

Table Shows the Threshold Values Considered for the Algorithm Applied to Determine Cloud Boundaries From the RH Profiles of the RS Soundings

\begin{tabular}{lccc}
\hline Altitude range & Minimum $\mathrm{RH}$ & Inter-RH & Maximum $\mathrm{RH}$ \\
\hline $0-2 \mathrm{~km}$ & $91 \%$ & $83 \%$ & $94 \%$ \\
$2-6 \mathrm{~km}$ & $89 \%$ & $80 \%$ & $91.5 \%$ \\
$6-12 \mathrm{~km}$ & $81.5 \%$ & $74 \%$ & $85 \%$ \\
$>12 \mathrm{~km}$ & $75 \%$ & $70 \%$ & $80 \%$ \\
\hline
\end{tabular}

Note. The column headers (minimum $\mathrm{RH}$, inter- $\mathrm{RH}$, and maximum $\mathrm{RH}$ ) are explained along with the algorithm in Appendix A. Inter-RH is the minimum $\mathrm{RH}$ value above which all RH values between two cloud layers must lie to classify the two layers as a single cloud, provided the distance between the layers is not greater than $300 \mathrm{~m}$. Refer to Appendix A for application of inter-RH in the algorithm used for this study.

balloons propagating toward the northwest direction at upper altitudes, for most of the launches, due to the southeasterly wind flow during the ISM.

\subsection{Cloud Detection From Radiosonde Soundings}

One of the earliest methods for determining cloud layers from vertical profiles of radiosondes/rawinsondes has been outlined by a technical report published by the Air Weather Service (1979) at the Scott Air Force Base at Illinois. The report delineates how to determine moist layers (clouds) from the RH profiles of radiosondes, by calculating the dew point depression, and defining sudden changes in the gradient of its profile as the boundary of a cloud. Building on this method, other studies suggested algorithms with certain modifications, for detecting cloud layers from RS soundings (Chernykh \& Eskridge, 1996; J. Wang, 1995; Minnis et al., 2005; Poore et al., 1995; Zhang et al., 2010).

Costa-Surós et al. (2014) analyzed various methods for detection of CVS from RS profiles, which included a method proposed by Dmitrieva-Arrago and Shatunova (1999) along with the five studies cited above. The study found that the algorithms by Poore et al. (1995), J. Wang (1995), and Zhang et al. (2010), which work on very similar approaches, performed better than the rest. The most recently modified method in this series of algorithms by Zhang et al. (2010) has been determined by this study as being the most effective, when compared to measurements from a ground-based system, Active Remote Sensing of Clouds. Considering this, the present study has also chosen to apply the same method for determining CVS from the RS soundings. From the study of Zhang et al. (2010), various threshold values within the suggested range were considered and CVS was calculated. After comparing the obtained CVS with collocated ceilometer observations and satellite observations (Global IR Network), the threshold values corresponding to maximum agreement between the observations and calculated CVS were considered for application in this study. The threshold values used in this study to apply the algorithm have been shown in Table 2, and the steps of the algorithm have been outlined in Appendix A.

The clouds obtained were then classified on the basis of the phases that they were present in. The freezing level (FL) remained relatively unchanged during the RS campaign period, fluctuating between a maximum of $6.09 \mathrm{~km}(\sim 490 \mathrm{hPa})$ and a minimum of $5.32 \mathrm{~km}(\sim 540 \mathrm{hPa})$. FL is defined as the height at which the temperature becomes $0^{\circ} \mathrm{C}$. Clouds were classified as (i) warm clouds when the base and top both fell below the FL, (ii) mixed-phase clouds when the base was below the FL and the top was above the FL, and (iii) cold clouds when base and top both were found to be above the FL. As can be understood from the names, warm clouds would consist of liquid water, cold clouds would have ice crystals, while mixed-phase clouds are expected to include all three - liquid droplets, ice particles, and supercooled liquid droplets.

\subsection{Calculation and Analysis of CRF}

CRF can be described as the change in net radiation caused by the clouds present in the atmosphere, compared to a clear-sky scenario where there are no clouds. Apart from observations of SW and LW fluxes at TOA, CERES data product, SYN1deg-3Hour, also provides values for clear-sky fluxes computed for surface as well as TOA. The term "clear sky" is used to define the condition where there are no clouds present and everything else remains the same. This term has been defined in order to isolate the effect of clouds from other factors that may be affecting radiation processes. The net CRF is given by

$$
\mathrm{CRF}_{\text {net }}=F_{\mathrm{all}}-F_{\mathrm{clr}}
$$


where $F_{\text {all }}$ and $F_{c l r}$ are radiation fluxes for cases of actual sky and clear (cloud-free) scenario. The concept and subsequent calculations for the application of equation (1) for TOA and surface measurements have been explained by Ramanathan et al. (1989). The change in net radiation is the summation of changes in SW and $\mathrm{LW}$ radiation and can be termed as SW forcing and LW forcing, respectively. Individually, the $\mathrm{SW}\left(\mathrm{RF}_{\mathrm{SW}}\right)$ and $\mathrm{LW}\left(\mathrm{RF}_{\mathrm{LW}}\right)$ forcing due to clouds can be given by the equations

$$
\begin{aligned}
& \mathrm{RF}_{\mathrm{SW}}=F_{\mathrm{s}, \mathrm{all}}-F_{\mathrm{s}, \mathrm{clr}} \\
& \mathrm{RF}_{\mathrm{LW}}=F_{\mathrm{l}, \mathrm{all}}-F_{\mathrm{l}, \mathrm{clr}}
\end{aligned}
$$

where $F$ stands for the radiation flux value, the subscripts " $s$ " and "I" stand for SW and LW radiation, respectively, and the subscripts "all" and "clr" stand for cloud-included cases and clear-sky cases, respectively. The net CRF is influenced by both the SW and LW radiation as shown in equation (4).

$$
\mathrm{CRF}_{\text {net }}=\mathrm{RF}_{\mathrm{SW}}+\mathrm{RF}_{\mathrm{LW}}
$$

Net CRF can thus be seen as the effective forcing after incorporating both the cooling and warming effects. In almost all cases, SW forcing values will be negative (cooling) and that of LW will be positive (warming). Thus, in general, a greater (lesser) SW forcing than LW forcing will cause net CRF to be negative (positive), that is, a net cooling (warming) effect.

While associating CRF with corresponding CVS parameters, all analyses of SW forcing have been carried out by using values of SW radiation only between $0930 \mathrm{LT}$ and $1630 \mathrm{LT}$, to ensure that SW radiation is not been erroneously measured during the hours of darkness.

After the CVS was obtained and the CRF was calculated, an analysis was performed to see how CVS and CRF varied during the $D$ and ND phases of the campaign. Extensive analyses were also carried out to associate the various parameters of the CVS with corresponding $\mathrm{CRF}_{\text {srf }}$ and $\mathrm{CRF}_{\text {toa }}$.

\section{CVS}

For the purpose of the present study, in all instances, the direction of scanning the vertical profile is upward from the surface, except if otherwise indicated. A cloud is defined as a layer in the atmosphere which has satisfied all conditions of the algorithm (explained in Appendix A). The atmospheric cloudy layer (ACL) stands for the layer of the atmosphere that contains all clouds within it. Hence, the $A C L$ is defined as starting at the base of the lowest cloud and terminating at the top of the highest cloud. Total depth stands for the sum total of the depths of all the clouds found in the atmospheric layer. So the total depth can be visualized as the depth of the ACL after all of the cloud-free air has been removed. The vertical cloud amount has been defined here as the fraction occupied by clouds in the vertical cross section. It is a ratio of total depth to the ACL depth. It can be useful in understanding the fractional cloud-occupied depth of the atmosphere if the base and top of the $A C L$ is known from surface and satellite measurements, respectively.

The RS soundings detected a total of 329 cloud layers from 137 launches, two of which did not detect any cloud layers - one on 10 July at 03:30 UTC, and the other on 12 July at around 14:45 UTC. The campaign period, after being divided into $D$ and ND phases (see Table 1), was analyzed with respect to the various parameters of CVS, in order to understand the depression/LPS phases of the ISM in the context of cloud structure. A complete visual representation of the CVS present during the campaign has been shown in Figure 3c. Overall, it is observed that the D phases are clearly marked by deep, convective cloud layers. The ND phases, however, cannot be characterized with distinct, identifying features.

Among the 329 total cloud layers, it was found that there were an almost equal ( $33 \%$ each) number of low layers (cloud base $<2 \mathrm{~km}$ ), midlevel layers ( $2 \mathrm{~km}<$ cloud base $<6 \mathrm{~km}$ ), and high layers (cloud base $>6 \mathrm{~km}$ ). However, as seen in Table 3, the first layer clouds were mostly low clouds. The vertical temperature profiles for the entire period have been shown in Figures $4 a$ and $4 b$, by segregating the profiles into the D and ND phases and representing the mean profile of each phase in the plot. The differences between the D and ND phases, in terms of the meteorological parameters, can also be observed in the pattern of $\mathrm{RH}$ conditions, with ND phases showing significantly lower $\mathrm{RH}$ values compared to those during the D phases (see Figure 4c), as far up as the midtroposphere. 
Table 3

Table Shows All Basic Statistical Values (Altitude From Ground), Separated By Phase, for CBH, Topmost Cloud Top Height, Depth of First Cloud, Depth of ACL, the Total Depth of All Layers, and Vertical Cloud Amount

\begin{tabular}{lccccccc}
\hline $\begin{array}{l}\text { Statistical } \\
\text { value }\end{array}$ & Phases & Base height $(\mathrm{km})$ & Top height $(\mathrm{km})$ & $\begin{array}{c}\text { First cloud } \\
\text { depth }(\mathrm{km})\end{array}$ & ACL depth $(\mathrm{km})$ & Total depth $(\mathrm{km})$ & $\begin{array}{c}\text { Vertical cloud } \\
\text { Amount (\%) }\end{array}$ \\
\hline Minimum & D1 & 0.076 & 3.924 & 0.448 & 3.615 & 1.718 & 37 \\
& ND1 & 0.133 & 1.401 & 0.094 & 0.094 & 0.094 & 9 \\
& D2 & 0.076 & 1.921 & 0.066 & 0.136 & 0.136 & 24 \\
& ND2 & 0.154 & 2.147 & 0.074 & 0.089 & 0.089 & 6 \\
& D3 & 0.076 & 3.141 & 0.221 & 1.751 & 0.659 & 18 \\
& D1 & 0.964 & 7.098 & 3.646 & 6.134 & 4.761 & 77 \\
& ND1 & 1.552 & 6.279 & 1.138 & 4.727 & 1.921 & 55 \\
& D2 & 0.752 & 7.738 & 2.433 & 6.986 & 4.291 & 67 \\
& ND2 & 3.088 & 8.938 & 0.618 & 5.850 & 2.037 & 49 \\
& D3 & 0.668 & 7.862 & 1.412 & 7.195 & 2.958 & 52 \\
& D1 & 0.737 & 7.124 & 3.071 & 5.753 & 4.520 & 79 \\
& ND1 & 1.127 & 6.633 & 0.656 & 4.444 & 1.563 & 52 \\
& D2 & 0.302 & 8.126 & 1.689 & 7.407 & 3.990 & 67 \\
& ND2 & 1.605 & 8.909 & 0.419 & 6.649 & 1.605 & 47 \\
& D3 & 0.467 & 7.491 & 1.180 & 6.147 & 2.653 & 61 \\
& D1 & 3.442 & 10.783 & 9.057 & 9.875 & 9.057 & 100 \\
& ND1 & 5.327 & 12.309 & 4.324 & 11.993 & 4.636 & 100 \\
& D2 & 6.966 & 14.162 & 8.731 & 14.084 & 8.731 & 100 \\
& ND2 & 9.530 & 13.168 & 4.140 & 10.778 & 5.355 & 100 \\
& D3 & 3.038 & 15.853 & 3.556 & 15.776 & 6.161 & 100 \\
\hline
\end{tabular}

Tables 3 and 4 have been compiled in order to provide a complete comparison between the different parameters of CVS during D and ND phases, with all important statistical terms. The comparison shows that common features can be seen across all the three $\mathrm{D}$ phases. $\mathrm{CBH}$ s were found to be closer to the surface during all D phases compared to the ND phases. The lowest $\mathrm{CBH}$ s were obtained at $76 \mathrm{~m}$ from ground level, and this was observed for all three $D$ phases, which indicate that the cloud began from the surface itself. Most of the nearsurface bases were detected during the depression phases. The mean and median values show that the $\mathrm{CBH}$ was lower for D2 and D3, compared to D1. In general, the cloud bases were farther away from the surface during ND, when compared to the $D$ phases. Figure $3 \mathrm{~b}$ shows the evolution of the level of free convection (LFC) and lifting condensation level (LCL) during the campaign, where a similar pattern can be observed. The LFC and LCL are higher during the ND phases, compared to the D phases when they are lower by almost $1 \mathrm{~km}$. However, there were differences between $\mathrm{CBHs}$ of both the ND phases too, specifically ND1 and the first 3-4 days of ND2. Overall, the base during ND1 is quite close to the surface compared to that during ND2. From an analysis of the behavior of wind direction during the campaign period, it was observed that during the first few days of phase ND2 (see Figures $4 \mathrm{e}$ and $4 \mathrm{f}$ ), there was a shift in the wind direction. It is commonly known that, during the ISM, surface winds and low-level winds ( $850 \mathrm{hPa})$ usually blow from the southeast (Gadgil, 2003; Rajeevan et al., 2013, respectively) over this region of northern India, and the same conditions were observed for the whole campaign, except during the initial part of ND2, when winds blew from the northwest. This could be an instance of a mesoscale dry air intrusion event, which could result in reduced precipitation amounts (Krishnamurti et al., 2010). Incidentally, a sudden rise in LCL and LFC and a corresponding dip in equilibrium point (EP) can be observed (see Figure $3 \mathrm{~b}$ ), during the same period that there was a change in the wind direction. This confirms that convective activity had suddenly become very low during this time, before resuming to normal levels 3-4 days later. The low convective activity during these initial days of ND2, impacted cloud formation, especially at lower altitudes and the observed clouds at greater heights may have been brought in by advection. This is not the case in ND1, where convection was relatively unperturbed, thus maintaining cloud formation activity and keeping cloud bases closer to the surface. 

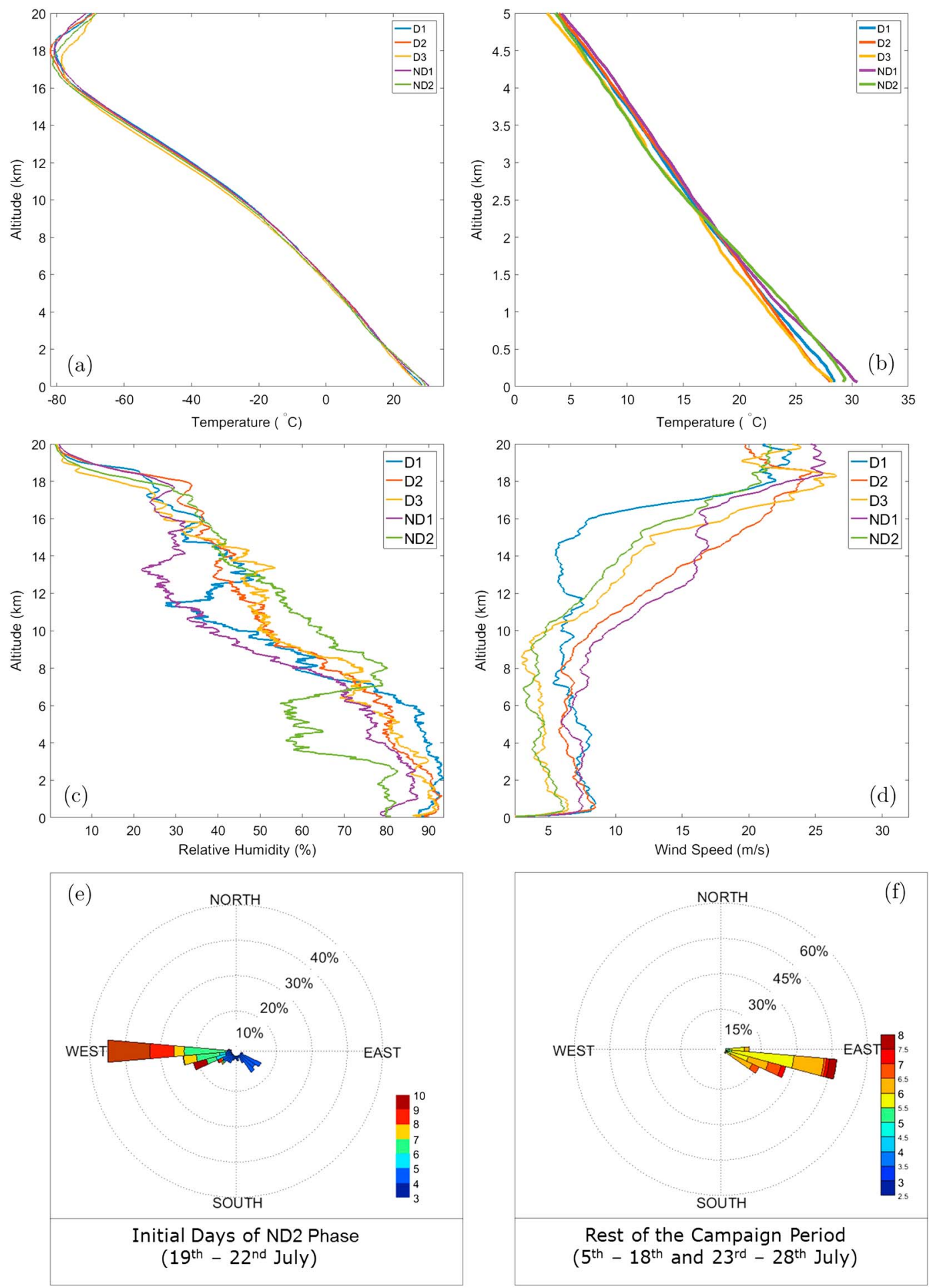

Figure 4. Mean vertical profiles of (a) temperature (up to $20 \mathrm{~km}$ ), (b) temperature up to $5 \mathrm{~km}$, (c) RH, and (d) wind speed, separated for the D phases and ND phases. The tropopause was observed at $\sim 17-18 \mathrm{~km}$ from the surface for all launches. Wind rose diagrams are shown indicating the frequency of wind intensity and direction during (e) the initial days of ND2 phase and ( $f$ ) the remaining campaign period. The values in the legend (shaded) are in units of $\mathrm{m} / \mathrm{s}$. The percentage numbers shown at the inside edge of each concentric circle indicates the frequency value at the circumference of that circle. Only winds up to an altitude of $10 \mathrm{~km}$ have been considered for the wind rose diagrams. 
Table 4

Table Shows All Basic Statistical Values (Altitude From Ground), Separated For D and ND Phases, for Mean Cloud Layer Base Height (in m), Mean Cloud Layer Top Height (in m), Mean Cloud Layer Depth (in m), and Vertical Cloud Amount for the Corresponding Layer (in \%)

\begin{tabular}{|c|c|c|c|c|c|c|c|c|}
\hline \multirow[b]{2}{*}{ Layer } & \multicolumn{2}{|c|}{ Mean base height (m) } & \multicolumn{2}{|c|}{ Mean top height $(\mathrm{m})$} & \multicolumn{2}{|c|}{ Mean depth $(\mathrm{m})$} & \multicolumn{2}{|c|}{ Mean vertical cloud amt } \\
\hline & $\mathrm{D}$ & ND & $\mathrm{D}$ & ND & $\mathrm{D}$ & ND & $\mathrm{D}$ & ND \\
\hline First layer & 791 & 2,332 & 3,320 & 3,206 & 2,529 & 874 & $43 \%$ & $35 \%$ \\
\hline Second layer & 4,410 & 5,182 & 5,545 & 5,915 & 1,135 & 733 & $18 \%$ & $14 \%$ \\
\hline Third layer & 7,228 & 7,088 & 8,296 & 7,837 & 1,068 & 750 & $13 \%$ & $9 \%$ \\
\hline Fourth layer & 9,007 & 7,873 & 10,089 & 9,092 & 1,082 & 1,220 & $14 \%$ & $14 \%$ \\
\hline Fifth layer & 8,724 & 9,643 & 9,056 & 9,837 & 333 & 194 & $3 \%$ & $2 \%$ \\
\hline Sixth layer & 6,433 & 11,807 & 8,341 & 11,880 & 1,909 & 73 & $23 \%$ & $1 \%$ \\
\hline
\end{tabular}

While cumulus, stratiform, and cirrus clouds were all observed during the period, most of the topmost cloud top heights are those of cold, cirrus clouds. Cirrus clouds were often present far higher than the cloud layers underneath them. The highest cloud top height was at an altitude of more than $15.8 \mathrm{~km}$, but such values exceeding $\sim 14 \mathrm{~km}$ were very rare. Unlike in the case of $\mathrm{CBH}$, no specific pattern could be observed for cloud top height in D and ND phases.

It was also observed from the analysis of cloud tops that with the exception of cirrus clouds, a high number of clouds ( $45-55 \%)$ terminated at the height of $\sim 8-10 \mathrm{~km}$. This suggests that there might be an inhibiting factor that prevents growth of clouds beyond this level. Sathiyamoorthy et al. (2004), in their study, analyzed the behavior of the TEJ in the upper troposphere, blowing during the summer monsoon and its relation with the high cloud amount and magnitude of CRF, over the Asian monsoon region. The study suggested that the TEJ may be responsible for inhibition of any cloud formation processes at pressure levels of around $300 \mathrm{hPa}$ and may thus give rise to unfavorable conditions for any cloud growth to occur above this. The vertical profiles of wind speed from the RS launches (see Figure 4d) show that wind speed increases drastically after 9 to $11 \mathrm{~km}$ from the surface, often reaching magnitudes exceeding mean values of $25 \mathrm{~m} / \mathrm{s}$. Further, the wind direction profiles showed these upper level winds to be coming from the east (see Figures $4 \mathrm{e}$ and $4 \mathrm{f}$ ).

Moreover, the EP (or the level of neutral buoyancy) mostly kept fluctuating between 9 and $11 \mathrm{~km}$ (see Figure 3b), and never went higher even during synoptic low-pressure events, indicating that during the entire campaign, there would have been no convection and thus cloud formation, beyond this altitude. The tendency of clouds to terminate at this level could thus be attributed to the TEJ, "capping-off" the convection and forming an anvil structure at such heights. The TEJ may also be responsible for the constant presence of high cloud amount (in agreement with Sathiyamoorthy et al., 2004) throughout July (as seen in Figure 2b); however, as cloud fraction values cannot be determined from RS soundings, this hypothesis cannot be confirmed. While the previous study has shown the correlation of TEJ with cloud tops stagnating at $300 \mathrm{hPa}$, it was based on satellite data and National Centers for Environmental Prediction-National Center for Atmospheric Research reanalysis. The present study is the first time such observations have been made regarding the same from collocated, in situ measurements. Hence, even if the cloud top height were to be influenced by depressions or LPS, this effect cannot be observed, as the TEJ inhibits convection beyond the $\sim 300 \mathrm{hPa}$ level, irrespective of the phase (D or ND).

The cloud depth varied to a great extent throughout the campaign as well as through the vertical profile. The maximum cloud depth was found to be $\sim 9 \mathrm{~km}$, while the minimum cloud depth was a mere $89 \mathrm{~m}$. The minimum cloud depth, however, could be restrained by the algorithm applied for detection of clouds, which considers a moist layer as cloud only if it has a minimum thickness of $30.5 \mathrm{~m}$ and $61 \mathrm{~m}$ (for CBHs lower than $2 \mathrm{~km}$ and higher than or equal to $2 \mathrm{~km}$, respectively). For almost all instances of heavy rainfall, the $A C L$ depth was visibly higher, because of shallow cloud bases and high cloud tops (see Figure 3c). The first cloud depth (FCD) tends to be relatively higher in the case of D phases, as can be seen from Table 3. It was also observed that the FCD was significantly higher during the D1 phase, compared to the other two D phases.

Most deep, convective clouds were found to be the first clouds encountered above the surface. More than $21 \%$ of the RS launches detected a cloud of depth $>3 \mathrm{~km}$ in the first layer. Subsequent layers almost always had a depth smaller than the first layer, except for approximately one third of the cases, where the depth of 

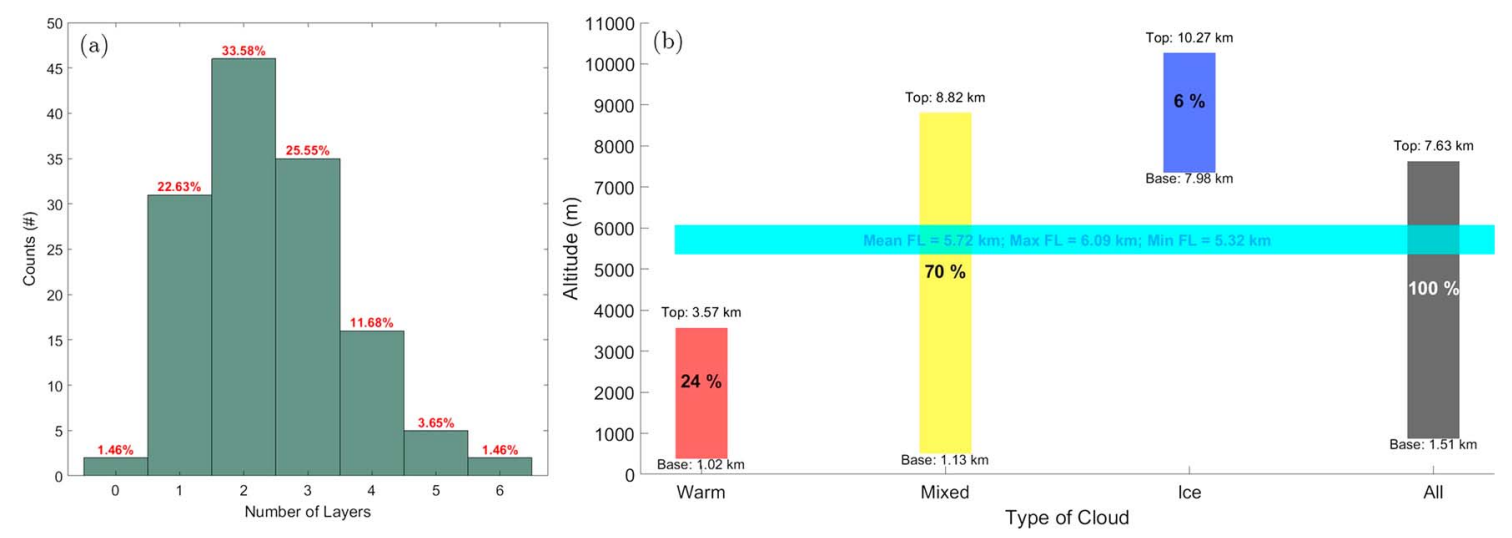

Figure 5. (a) Occurrence of cloud type obtained during the radiosonde campaign, classified based on phase; values mentioned at the top and bottom indicate mean heights for the particular group, and the values within the boxes indicate the number of data points in each bin. Clouds (bottom to top layer) with top below the freezing layer (FL) are considered warm, clouds with base below FL and top above FL are considered mixed, and those with base above FL are considered ice (cold) clouds. (b) Frequency distribution of the number of cloud profiles detected during the RS campaign. Warm profiles indicate presence of only clouds below the FL (no ice clouds), while ice profiles indicate presence of clouds only above FL (no warm clouds). The mixed-phase profiles may contain warm, mixed as well as ice-phase clouds. The values within the bars indicate number of instances the corresponding number of layers were detected, and the percentage values shown above the bars (in red) indicate the proportion among the total launches.

the second layer was quite large compared to the others. These cases did not feature as a significant majority in either the D or ND phases.

This provides an insight into what might be the usual depth of clouds that are present in this region during the ISM, at various periods in the life cycle of a monsoon depression. However, it must be noted that in spite of heavy convection processes and supporting conditions available, the cloud depth rarely reached $\sim 10 \mathrm{~km}$, due to the inhibition of cloud formation by the TEJ. A correct representation of cloud depth in models becomes important because of the implication it will have on several other parameters, such as CRF, the circulation in the atmosphere as well as precipitation mechanisms.

An analysis of the type of clouds classified on the basis of phases (see Figure $5 \mathrm{~b}$ ) revealed that the majority of the launches ( $70 \%)$ found the atmospheric cloudy layer to be in the mixed-phase, followed by warm clouds ( 24\%) and ice clouds ( 6\%). It can be observed (Figure 3c) that during almost the entire campaign period, except ND1 and 1 day in D3, the cloud top height remained above the FL ( $5.5 \mathrm{~km})$. With the exception of one launch on 11 July, all the other ice clouds were observed during the ND2 phase, which as discussed above had been affected by a dry air intrusion. This was also reflected in the fact that out of the 32 observed warm layers, only 2 were during the ND2 phase (consisting of 7 days), with cloud depths much below average. The lack of cloud growth processes due to this change in wind direction (see Figures $4 \mathrm{e}$ and $4 \mathrm{f}$ ) and temperature (see Figures 4a and 4b) may be assigned as the reason behind the dearth of usually observed mixed-phase clouds at this time. Warm clouds occurred almost equally as single-layer and two-layered structures. While the tops were below the FL, warm clouds were also still generally deep clouds, with almost half of them exceeding the median depth of $2.8 \mathrm{~km}$. The abundance of mixed-phase clouds during the rest of the campaign period, especially the $D$ phases, gives an indication of the strong convective activity going on over the region during this period.

More than 98\% launches (135 out of 137) detected at least one cloud layer, and as shown in Figure 5a, more than $75 \%$ (104 out of 137) of all launches detected multilayered clouds. Although CVS has been previously studied over this region, former studies have mostly used satellite measurements and have only provided vertical information regarding microphysical properties (Rajeevan et al., 2013; Ravi Kiran et al., 2015). Thus, this is the first in situ, observational evidence supporting the multilayer cloud structure present during the ISM, over the IGP region.

While the maximum number of multiple simultaneous layers (6 layers) present was as rare as instances where no clouds were obtained (twice each), clouds most frequently occurred in two-layered ( $34 \%$ of the time), followed by three-layered $(\sim 26 \%)$, and then single-layered structures $(\sim 23 \%)$. The frequency distribution shown in Figure 5a gives an idea of the most probable number of layers that could be present during the monsoon period over this region. This information could be particularly useful in improving radiation 
calculations in models and also for aerosol-cloud studies, which almost always assume single-layered cloud structures.

From studies such as Lopez et al. (2008) and Bony et al. (2016), we can understand the importance of incorporating CVS results into tropical cloud-resolving models and general circulation model parameterizations, respectively, which would help immensely in the simulation of results that are closer to true conditions.

\section{CRF}

The TOA radiation measurements and the values for clear-sky SW and LW radiation fluxes at the surface as well as TOA have been obtained from CERES, while those for surface measurements of radiation are from the flux tower at IITK. For $<1 \%$ of the SW forcings, positive values were obtained. Considering the reason behind this to be measurement errors by the instrument, these values have been excluded from the study.

The mean values $( \pm S D)$ for $\mathrm{SWCRF}_{\text {sff }}$ and $\mathrm{SWCRF}_{\text {toa }}$ are $-95.92( \pm 135.21) \mathrm{W} / \mathrm{m}^{2}$ and $-101.89( \pm 116.67) \mathrm{W} / \mathrm{m}^{2}$, respectively. These are much higher than the global mean values of $-44.5 \mathrm{~W} / \mathrm{m}^{2}$ that Ramanathan et al. (1989) observed at TOA from the ERBE experiment. These results were for April, whereas this study measures CRF for July, when the monsoon is at its peak. However, the measurements here are within the range of values obtained by Saud et al. (2016), who observed $-82.7( \pm 24.5) \mathrm{W} / \mathrm{m}^{2} \mathrm{SWCRF}_{\text {toa }}$ during the ISM at TOA. The maximum values for $\mathrm{SWCRF}_{\text {sff }}$ and $\mathrm{SWCRF}_{\text {toa }}$ are $-616.90 \mathrm{~W} / \mathrm{m}^{2}$ and $-498.87 \mathrm{~W} / \mathrm{m}^{2}$, respectively.

A similar comparison of the mean LWCRF $_{\text {toa }}$ obtained in this study $\left(66.55 \pm 41.18 \mathrm{~W} / \mathrm{m}^{2}\right)$ and the global mean by Ramanathan et al. (1989) $\left(31.3 \mathrm{~W} / \mathrm{m}^{2}\right)$ shows that the values obtained for this region and period are much higher. The range of $\operatorname{LWCRF}_{\text {toa }}\left(53.7 \pm 14.2 \mathrm{~W} / \mathrm{m}^{2}\right)$ by Saud et al. (2016) for July over India, however, agrees well with this study. The maximum value of $L W C R F_{\text {toa }}$ is $159.81 \mathrm{~W} / \mathrm{m}^{2}$. The mean and maximum $L_{W C R F}$ srf $15.33 \pm 11.06 \mathrm{~W} / \mathrm{m}^{2}$ and $66.55 \mathrm{~W} / \mathrm{m}^{2}$, respectively.

Although there are no studies yet that have calculated the CRF values at surface, studies such as Allan (2011) and Su et al. (2010) have computed surface CRF values at a global scale. Both studies have used CERES measurements along with model outputs. While Allan (2011) obtained SWCRF and LWCRF values of $-52.8 \mathrm{~W} / \mathrm{m}^{2}$ and $32.7 \mathrm{~W} / \mathrm{m}^{2}$, respectively, values obtained by Su et al. (2010) are in the range of -42 to $-46 \mathrm{~W} / \mathrm{m}^{2}$ and 22 to $29 \mathrm{~W} / \mathrm{m}^{2}$, respectively. The values obtained in this study can be considered quite high compared to the values in the studies mentioned here. However, it may be noted that this study focuses on a heavy monsoon period, and the larger values of SW forcing are expected. The LW forcing, on the other hand, agrees much better with values from Su et al. (2010) than those from Allan (2011).

The values of SW and LW forcing (see Figures 3d and 3e) show that SWCRF is greater by an order of magnitude in comparison to LWCRF. Hence, during the monsoon, clouds over this region clearly show a net cooling effect. Kiehl (1994) and Ramanathan et al. (1989) observed near cancellation of SW and LW forcing over the tropical regions, thus delicately maintaining a radiation balance. However, this study shows that during the monsoon period, over this region, clouds are responsible for a large amount of net cooling at the surface as well as TOA. Rajeevan and Srinivasan (2000), Saud et al. (2016), and S. D. Patil (2005) have also found supporting observations at TOA.

There is a clear difference in the magnitude of CRF values between $D$ and ND periods, with significantly higher forcing being observed during the $D$ periods, at both the surface and TOA, with the period between 22 and 24 July being an exception. A comparison between the CRF values, especially SWCRF, with the RV during the campaign (see Figures $3 a, 3 d$, and $3 e$ ), shows similar trends between the two, except for the period between 22 and 24 July.

The values of $\mathrm{LWCRF}_{\text {toa }}$ are much higher than $\mathrm{LWCRF}_{\text {srf }}$, while those of SWCRF are almost the same for surface and TOA. A probable reason for this could be the heavy dependence of SWCRF on cloud depth, which would mean no change at TOA and surface. However, LWCRF would depend on depth as well as location. The base height may be influencing LWCRF $_{\text {sff }}$, and the top height may be influencing LWCRF $_{\text {toa }}$. This might be a possible reason for the change observed at the surface and at TOA. To examine this further, CRF has been associated with the different parameters of CVS in the subsequent section.

\section{Relating CVS With CRF}

Considering that the first cloud layers are usually the deepest, an analysis was made to check how much of the forcing depended on the thickness of the first cloud alone. Figures $6 \mathrm{a}-6 \mathrm{~d}$ shows the relationship between 

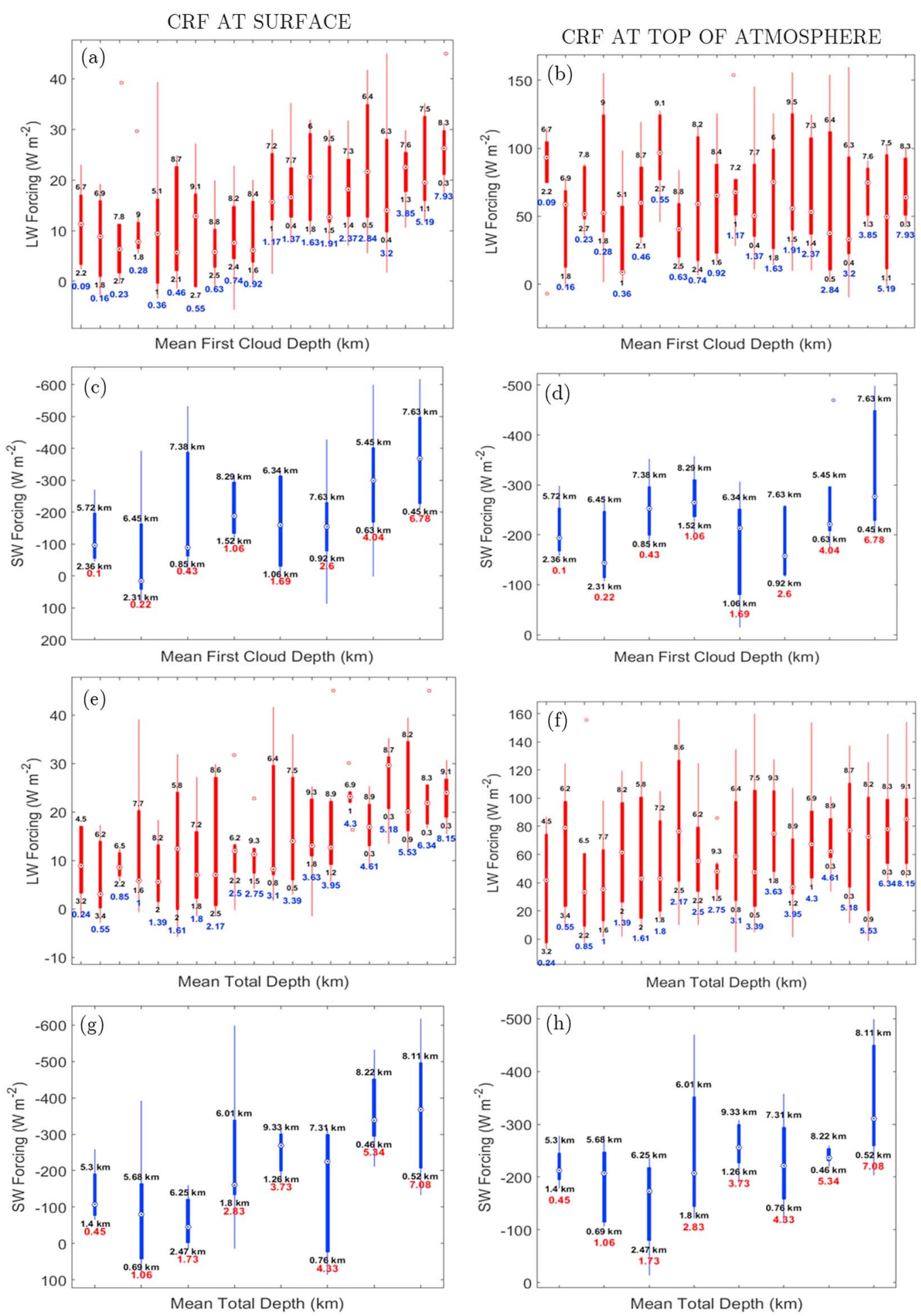

Figure 6. Associations between FCD and (a) LWCRF srf (b) $\mathrm{LWCRF}_{\text {toa }}$ (c) SWCRF srf , and (d) SWCRF toa and associations

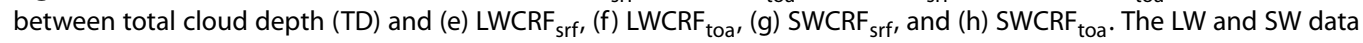
points have been divided into bins of 5 percentiles ( 20 bins) and 12.5 percentiles ( 8 bins), respectively, each bin containing $\sim 7-8$ data points. Markers within boxes indicate median value. The top and bottom of the boxes indicate the 75th and 25th percentiles of the respective bins, and the lines stretch out to the 5th and 95th percentiles. Any point lying outside this range is shown by a circle. The values shown on top of the box indicate the mean cloud top for the bin, and the upper value below the box indicates the mean cloud base for the bin. Values on $X$ axis are mean values of the respective parameter for the corresponding bin. These values have been mentioned below the boxes for each bin in colored font. 
SWCRF or LWCRF and the FCD. The correlation of $\mathrm{CRF}_{\text {srf }}$ with depth of the first layer is strong. However, the same cannot be said about $\mathrm{CRF}_{\text {toa }}$, which has no clear correlation with the FCD. This may be partly due to the interaction of the layers present above the first layer, which occurred in most of the cases.

It can be noted that Figures $6 \mathrm{e}-6 \mathrm{~h}$ show a clear increasing relationship between the total cloud depth and $\mathrm{CRF}_{\text {srf }}$ as well as $\mathrm{CRF}_{\text {toa }}$. However, the dependence of $\mathrm{LWCRF}_{\text {toa, }} \mathrm{LWCRF}_{\text {srf }}$, and SWCRF $\mathrm{Srf}_{\text {sf }}$ on the total depth of cloud layers seems to be stronger than that of SWCRF ${ }_{\text {toa. }}$. Rajeevan and Srinivasan (2000) and Ravi Kiran et al. (2015) have shown that the LWCRF toa increases with increase in cloud optical depth (COD); however, for COD $>10$, the values tend to become constant. Hence, it could be said that the LWCRF toa becomes independent

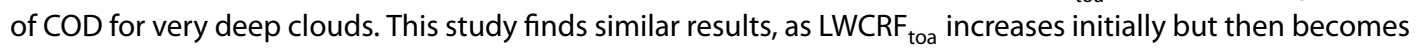
constant at high mean values of total depth.

As understood from the CVS obtained from the RS launches, deep, convective clouds almost always have their bases close to the surface. In the same light, clouds with very high bases are not expected to have large depths. Thus, carrying out an analysis of merely comparing CRF with cloud base may show a strong relation of increasing CRF with lower bases. However, this could actually just be a representation of increasing CRF with increasing cloud depth, due to the reasons mentioned above. In order to distinguish the effect of cloud base on CRF from that of cloud depth, Figures $7 a-7 d$ also incorporates the mean depth of the bins that are placed in increasing order of $\mathrm{CBH}$. A comparison between bins with similar mean depth shows that a trend between

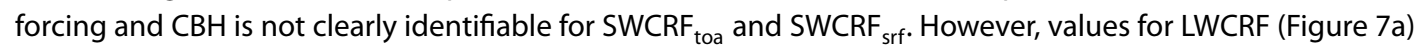
are observed to be reducing with increasing $\mathrm{CBH}$, even in cases where the depth tends to remain the same. If the cloud depth was actually influencing the LW forcing, the LWCRF similar relationship, just like both Figures $7 c$ and $7 d$ are showing for SWCRF srf $_{\text {and }}$ SWCRF toa, $_{\text {, }}$ respectively.

Table 5 gives values of slope and regression coefficients for the associations made between CRF and CVS parameters. This is to quantify the trend being observed in these associations. To calculate the slope and regression coefficients, the points considered are mean values of CRF values segregated into bins of equal percentiles (same bins as in Figures 6 and 7), with $\sim 7-8$ values considered for calculating each mean value. Although, for some trends, it is quite clear that the fitting curve would not be linear, for the sake of observing overall trends, a linear fit has been maintained for all associations here.

The association of cloud depth (for first cloud as well as total depth) can be clearly seen in the linear fit of mean values as shown in Table 5. The quantified parameters indicate clearly the dependence of SWCRF on depth of cloud, especially at surface. While the LWCRF is being influenced by the depth of clouds, the variation observed is quite less, as can be understood from the low value of slopes seen in the association of LWCRF with depth. The strongest influence of cloud depth is seen on SWCRF at the surface, especially by the depth of the first cloud above the surface, with a significant slope value as well as regression coefficient.

Figures $7 e-7 h$ clearly shows that the $\mathrm{CRF}_{\text {srf }}$ has no relation with the height of cloud top. This also holds true for SWCRF $_{\text {toa }}$. This could be because SWCRF toa $_{\text {a }}$ depends on cloud albedo, which is a function of cloud amount and cloud optical depth. The only forcing which seemed to be influenced by the cloud top height was LWCRF toa. This result may be due to cooler temperatures as clouds reach higher altitudes, thus emitting less energy than they would at lower altitudes. However, as can be seen from Figure $7 f$, it is also difficult to isolate the influence of cloud depth on forcing from that of cloud top height, because the cloud depth, in most cases, would increase along with the mean cloud top height.

This association of cloud base and top height regulating the LWCRF at surface and TOA, respectively, can also be observed in Table 5, where the trends of these associations have been quantified. SWCRF shows poor correlation with both the base and top height at the surface as well as at TOA, while on the other hand, LWCRF shows a clear influence of cloud location, by means of the significant values of regression coefficients and slopes.

A detailed insight into how cloud top and base heights influence CRF can be obtained by combining these individual analyses of base and top (Figure 7), with the influence of cloud phase on CRF (shown in Figure 8), which would give an idea about how cloud location affects CRF.

Such an analysis of the association of CRF with the phase of clouds is shown in Figure 8. The influence of phase on forcing cannot be isolated from that of the cloud geometrical parameters such as base height, top height, and mean depth, because a cloud's phase depends exclusively on its location relative to the FL. This, however, 
CRF AT SURFACE

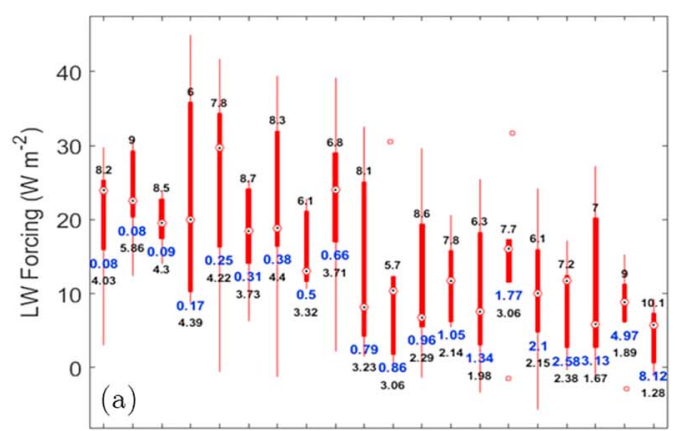

Mean Cloud Base Height ( $\mathrm{km})$

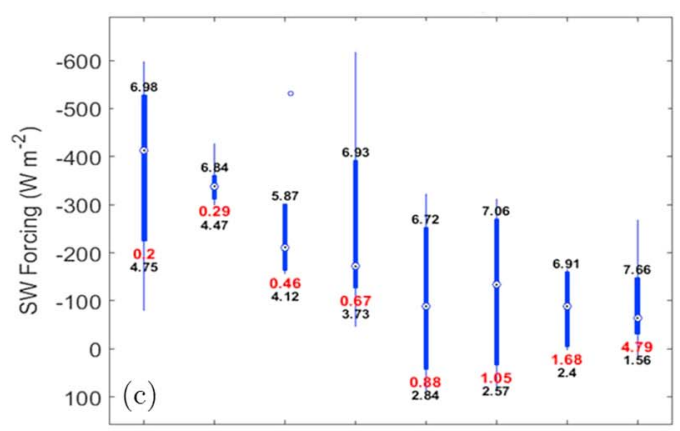

Mean Cloud Base Height (km)

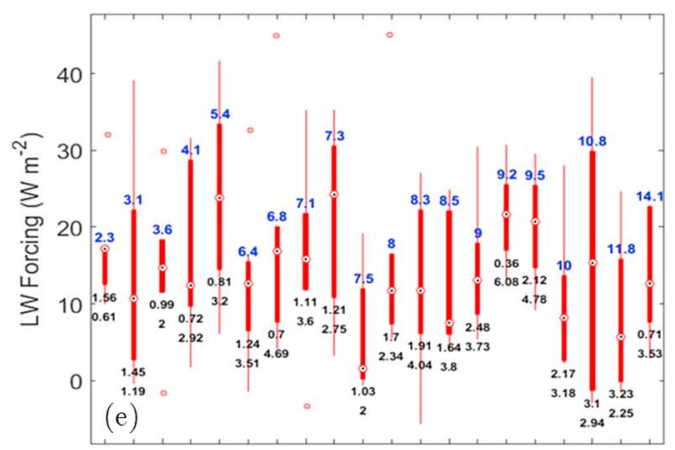

Mean Cloud Top Height $(\mathrm{km})$

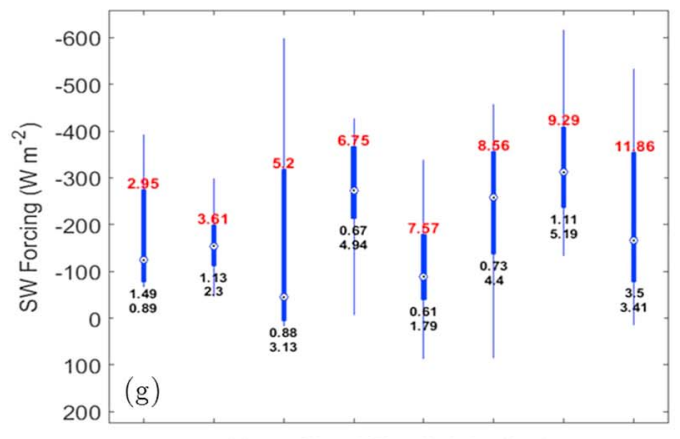

Mean Cloud Top Height $(\mathrm{km})$
CRF AT TOP OF ATMOSPHERE

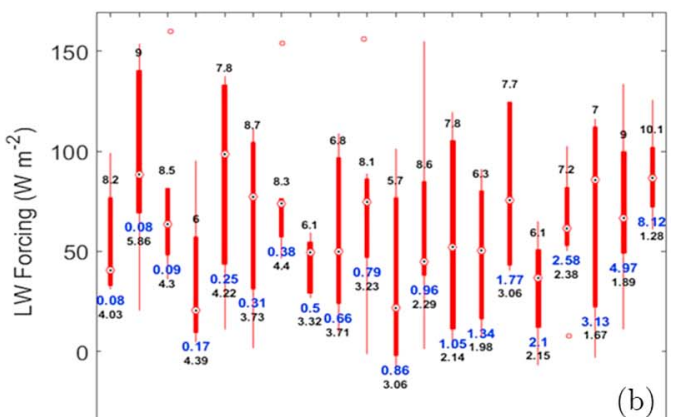

Mean Cloud Base Height (km)
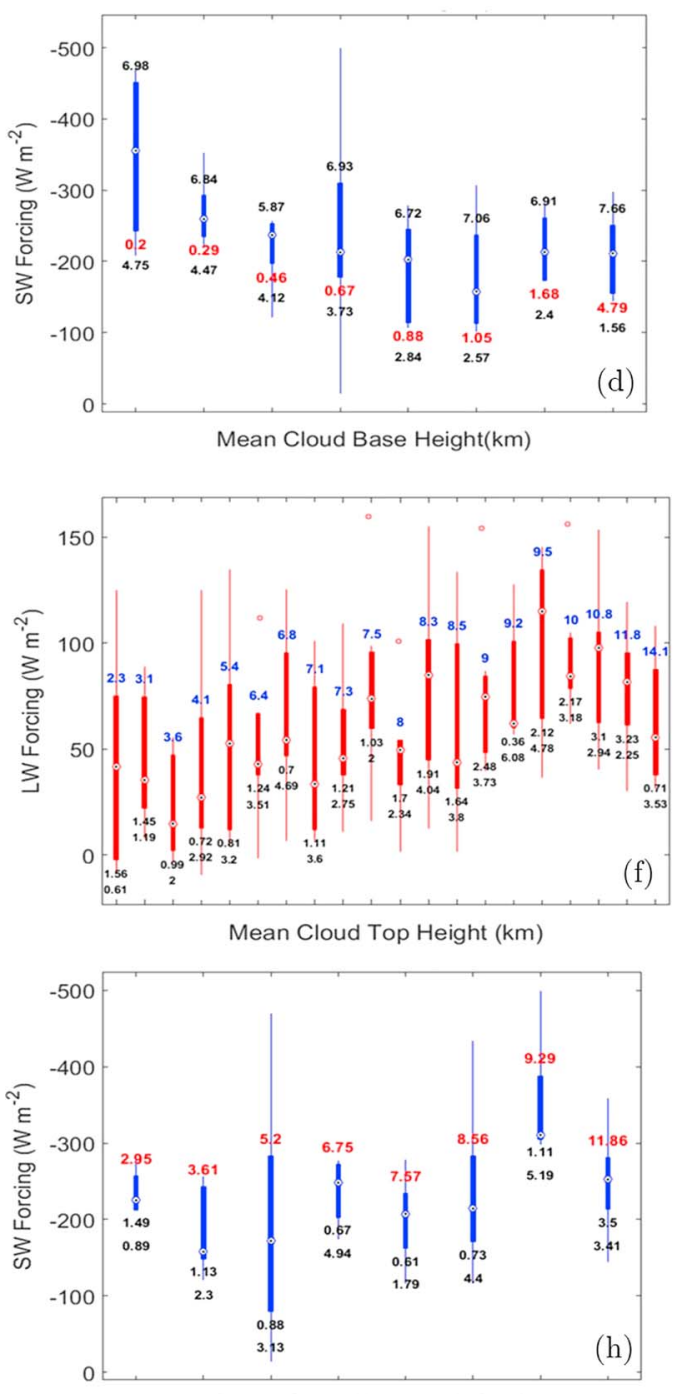

Mean Cloud Top Heiaht( $\mathrm{km})$

Figure 7. Associations between CBH and (a) $\operatorname{LWCRF}_{\text {srf }}$ (b) $\mathrm{LWCRF}_{\text {toa' }}$ (c) SWCRF srf $_{\text {, and (d) SWCRF }}$ toa and associations between cloud top height and (e) LWCRF srf (f) LWCRF LWa $_{\text {to }}$ (g) SWCRF srf $_{\text {, and (h) SWCRF }}$ toa. The LW and SW data points have been divided into bins of 5 percentiles ( 20 bins) and 12.5 percentiles ( 8 bins), respectively, each bin containing 7-8 data points. Markers within boxes indicate median value. The top and bottom of the boxes indicate the 75th and 25 th percentiles of the respective bins, and the lines stretch out to the 5 th and 95 th percentiles. Any point lying outside this range is shown by a circle. The values shown on top of the box indicate the mean cloud top for the bin, and the upper value below the box indicates the mean cloud base for the bin. Values on $X$ axis are mean values of the respective parameter for the corresponding bin. These values have been mentioned below the boxes for each bin in colored font. 
Table 5

Linear Fit of Mean of CRF Values (SW and LW) With Cloud Structure Parameters, Where Associations Have Been Fit Linearly Providing Values of Slope As Well As Regression Coefficients $\left(R^{2}\right)$ for Each Association's Value at Surface As Well As TOA

\begin{tabular}{|c|c|c|c|c|c|c|c|c|}
\hline \multirow[b]{4}{*}{ CVS parameter } & \multicolumn{8}{|c|}{ CRF parameter } \\
\hline & \multicolumn{4}{|c|}{ SWCRF } & \multicolumn{4}{|c|}{ LWCRF } \\
\hline & \multicolumn{2}{|l|}{ Surface } & \multicolumn{2}{|l|}{ TOA } & \multicolumn{2}{|c|}{ Surface } & \multicolumn{2}{|l|}{ TOA } \\
\hline & Slope $\left(\times 10^{-3}\right)$ & $R^{2}$ & Slope $\left(\times 10^{-3}\right)$ & $R^{2}$ & Slope $\left(\times 10^{-3}\right)$ & $R^{2}$ & Slope $\left(\times 10^{-3}\right)$ & $R^{2}$ \\
\hline FCD & -41 & 0.81 & -16 & 0.43 & 2.5 & 0.73 & 0.29 & 0.0016 \\
\hline Total cloud depth & -49 & 0.70 & -20 & 0.61 & 2.7 & 0.80 & 4.4 & 0.44 \\
\hline $\mathrm{CBH}$ & 57 & 0.42 & 13 & 0.13 & -2.3 & 0.55 & 2.1 & 0.051 \\
\hline Cloud top height & -12 & 0.20 & -8.9 & 0.26 & -0.36 & 0.057 & 4.8 & 0.48 \\
\hline
\end{tabular}

Note. The values for slope are calculated by best fitting the trend line to the equation $y=m(x)+c$, where $y$ is the CRF parameter, $x$ is the CVS parameter, $m$ is the slope, and $c$ is the intercept.

produced interesting observations, giving a better insight into how cloud vertical location (and thus, phase) can have different impacts on the SW and LW forcing, at surface and at TOA.

As explained earlier, clouds were differentiated into warm, cold, and mixed phases on the basis of their location with respect to the $F L$. The mixed clouds showed maximum impact on $\mathrm{SWCRF}_{\text {sff }}$ as well as $\mathrm{SWCRF}_{\text {toa }}$. This could be attributed to the fact that mixed clouds had the highest mean depth, significantly higher than warm and cold clouds. There was not much difference between SWCRF due to cold clouds was almost half of that found in warm clouds, in spite of cold clouds having a higher mean depth. This could be due to the influence of $C B H$ on $\mathrm{SWCRF}_{\text {srf }}$, as was also observed earlier in Figure 7c.

Contrary to the observations for SWCRF, the phase of clouds did not impact LWCRF via their mean depth. Instead, it was observed that the trend of $\mathrm{LWCRF}_{\text {srf }}$ was opposite to that of $\mathrm{LWCRF}_{\text {toa }}$. This clearly showed that the influence of cloud location on CRF was more dominant compared to that of cloud depth. The values
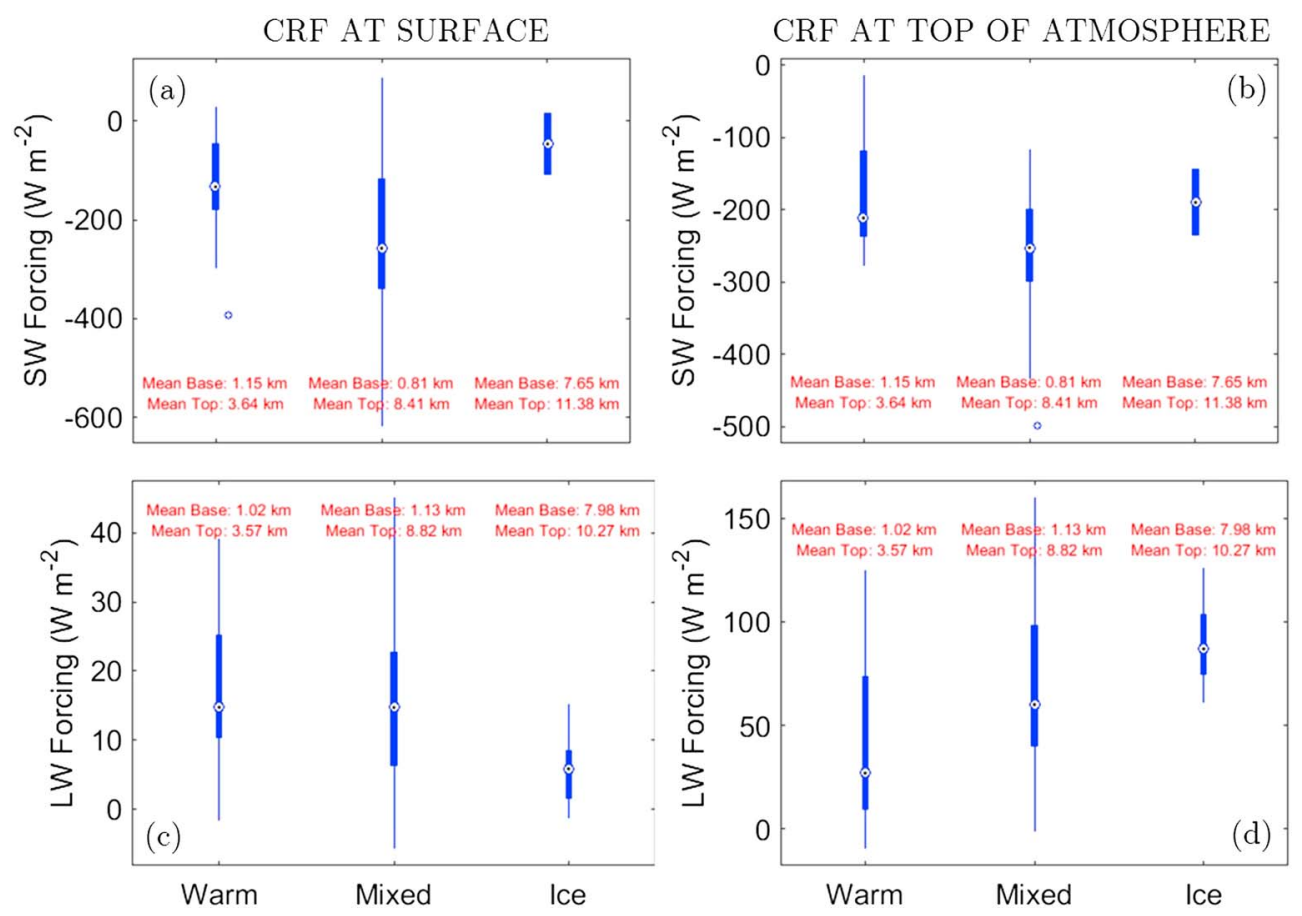

Figure 8. Association of the type of cloud, classified on the basis of phase with (a) SW $W_{\text {srf }}$ (b) $\mathrm{SW}_{\text {toa }}$ (c) $\mathrm{LW}_{\text {srf }}$, and (d) $\mathrm{LW}_{\text {toa }}$. The marker within the box indicates the median value for the bin. The top and bottom of the boxes indicate the 75 th and 25 th percentiles of the respective bins, and the lines stretch out to the 5th and 95th percentiles. Any point lying outside this range is shown by a symbol. The mean cloud base and top height for the respective phases have been mentioned in-line with the boxes. 
for LW forcing at surface (TOA) decreased (increased) for warm, mixed, and ice clouds in that order. Thus, as observed in Figures 7a and 7f, CBH and cloud top height influenced LWCRF $_{\text {srf }}$ and LWCRF toa $_{\text {, }}$ respectively.

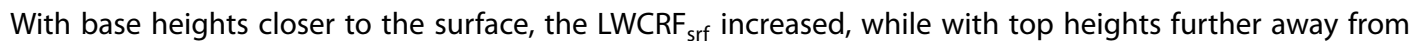

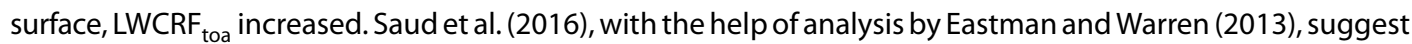
that LW emission from low clouds is higher compared to clouds at higher altitudes. This is because high clouds, with colder cloud top temperatures, will emit lesser energy by radiation compared to that by low clouds. Hence, $\operatorname{LWCRF}_{\text {srf }}\left(\mathrm{LWCRF}_{\text {toa }}\right)$ due to low clouds will be higher (lower) than that due to higher clouds.

A better perspective on how cloud structure influences radiation can be obtained by comparing two opposite scenarios, that is, low, thick clouds and high, thin clouds. Thick clouds located closer to the surface would reflect more solar radiation (because of their increased depth and thus optical thickness) and emit LW radiation almost as much as the surface (because temperature at lower altitudes would not be dissimilar to that at ground level). However, thinner clouds away from the surface would allow most of the solar radiation to pass through (because of low COD) but absorb more LW radiation, as well as emit back to TOA at much colder temperatures than that at the surface. In the case of deep clouds, with relatively low bases and high tops, SW and LW forcing would both increase at TOA, but at the surface, there would be a reduction in the value of LW forcing compared to that at TOA, while SW forcing would remain almost the same at both ends. SW forcing depends only on the cloud depth of clouds and is independent of the cloud location; however, LW forcing depends on both the location as well as depth. The amount of absorption of LW will be controlled by the cloud depth; however, the amount of LW emitted either to TOA or surface would depend on the cloud vertical location. Thus, even though cloud depth is an influencing factor, we see that the cloud base and top heights cause significant change in the forcings at the surface and TOA, respectively.

\section{Limitations and Conclusions}

\subsection{Possible Limitations of This Method}

This method is not free of limitations, and there could be instances when the algorithm misses a cloud layer or considers one where there is not any. This is especially true in cases where scattered clouds are present. The soundings from radiosondes effectively act more as point measurements than spatially averaged ones. Hence, it is possible that sometimes the radiosonde may have passed through clear gaps, in cases of scattered clouds, thus giving a misrepresentation that the air at that altitude was cloud free. Cases where broken clouds or completely overcast conditions are present would seem to be more reliable in this sense. As these scattered patterns are expected at higher altitudes (especially with cirrus clouds), one could say that the information at lower altitudes would be more reliable than that at greater heights, where the radiosonde may have missed a cloud, or by chance, encountered a small patch of cloud in an otherwise cloud-free area.

While cloud bases are usually relatively flat and devoid of major undulations, the same cannot be said about cloud tops. Hence, it is likely that the cloud top information is specific to the site that the radiosonde passed through and does not reflect the actual height of the cloud top if it were measured at a coarser spatial resolution. The horizontal drift in the course of some balloon launches could also lead to measurements that have been taken far enough away from the launch site to be considered not representative of the scenario in the study area. Moreover, even though MODIS suggests a high cloud fraction value present during the study period, it could be due to the constant presence of high altitude clouds. Thus, the drift in the path of the balloon could be causing it to observe a different cloud system as opposed to the one present above the launch site. However, as maximum drifts below the $15 \mathrm{~km}$ altitude were usually less than $50 \mathrm{~km}$, the chances of RS being in different cloud systems when rising through its vertical profile can be considered a fairly rare event. Another factor to be considered while studying CVS from RS profiles is that the balloon takes up to two hours (sometimes more or less, depending on the vertical wind velocity) to reach the tropopause. Thus, the measurements taken are spread over a considerably long period, enough for the weather conditions at nearsurface altitudes to have changed by the time the RS makes observations at higher altitudes.

During the monsoon, factors such as high $\mathrm{RH}$ at surface, fog, drizzle, and even rain can cause the algorithm to confirm a cloud from the surface itself (Zhang et al., 2010). This is a limitation of the algorithm, which is unable to distinguish between moist layers and clouds, especially at near-surface altitudes.

Since we have merged together several sources of data in this study, here we emphasize the possible limitations of this work. The RS41 radiosonde employed has been tested under standard conditions in various 
studies (Jauhiainen et al., 2014; Jensen et al., 2015), and the maximum combined uncertainty in sounding for temperature, $\mathrm{RH}$, and pressure was $0.4^{\circ} \mathrm{C}, 4 \%$ (for a confidence level of $95.5 \%$ ), and $1 \mathrm{hPa}$, respectively. However, it may be noted that this range of uncertainty covers cases when the RS is making measurements in extreme conditions, such as $>16 \mathrm{~km}$ altitude. Uncertainties may also be present from the values obtained from CERES. Overall, for $<1 \%$ cases, it was found that SWCRF values came to be positive. Such values were removed from the study, being considered as cases when erroneous measurements were made either from the surface radiometer or CERES itself. Moreover, a study by Thampi and Roca (2014) found a maximum uncertainty of $<5 \%$ for CERES-derived CRF values. The possible bias in MODIS measurements of cloud fraction also should be kept in mind, as mentioned above in the limitations.

Hence, certain inherent assumptions are made, when analyzing the CVS obtained from RS soundings. One of these is that there is not much change in the cloud structure over the duration of the balloon flight. Another assumption is that the measurements taken by the RS are taken as representative of the clouds over a greater region, in order to accommodate the measurements due to drift as well as those that encounter outlier situations, especially at cloud top levels.

\subsection{Conclusion}

An analysis of the CVS obtained from a radiosonde campaign over Kanpur in July 2016 was carried out, and information regarding the cloud base, top, depth, and the presence of a multilayered structure were obtained. These were then analyzed in terms of change in structure during D and ND phases. A total of 329 clouds were obtained, and other than 2 out of 137 RS launches, all detected at least one cloud layer. An equal distribution of low, middle, and high clouds was found; however, there was a clear variation in the frequency of warm, mixed, and cold phase clouds, with deep convective, mixed-phase clouds ( $70 \%)$ being in the highest amount, followed by warm ( 24\%) and cold ( 6\%) phase clouds.

For the $\mathrm{D}$ periods of study, cloud bases were significantly closer to the surface and the cloud depths were significantly higher, compared to the ND periods. Cloud top heights did not vary between D and ND periods, because of a more dominant presence of the TEJ, which inhibited cloud growth above $\sim 300 \mathrm{hPa}$. An analysis of a possible dry air intrusion affecting convection was also carried out for the ND2 period, which showed very high cloud bases, compared to the rest of the campaign period.

For more than $\sim 75 \%$ of cases, multilayered clouds were found to be present. The presence of two-layered cloud structures were found to be the highest ( 34\%) during the study period, followed by three- and onelayered structures. The maximum number of simultaneous layers obtained was six, however.

From an analysis of $\mathrm{CRF}_{\text {toa }}$ and $\mathrm{CRF}_{\text {sff }}$, it was observed that the SW forcing dominated the LW forcing by at least an order of magnitude during daytime, thus resulting in a net cooling effect both at the surface and TOA. The LW forcing, however, dominated during the night due to the absence of incoming solar radiation. Furthermore, a clear difference could be observed in the magnitude of forcing between the D and ND periods. There was also a difference observed between the two ND periods, where forcing magnitudes were relatively higher in ND2. As explained above, there was a difference in the mean CBH observed between the two phases and hence, these results suggest that cloud vertical location could be an influencing factor on CRF.

Associations were also made in order to understand the associations between the various parameters of CVS and the SW and LW forcing at the surface and TOA. It was found that the cloud depth heavily influences both SW and LW forcing at TOA as well as at the surface. However, the FCD did not affect the forcing magnitudes at TOA. The cloud base and top heights were also compared with corresponding forcing values, and associations were seen, but it was difficult to isolate the impact of cloud depth from these. It was still observed that the base heights and top heights influenced forcing at the surface and at TOA respectively. The phase of clouds also was responsible for influencing the forcing, because of factors such as cloud vertical location and variation in mean depth observed for the different phases.

Thus, the present study provides a complete observational profile of cloud characteristics for periods of depressions and low-pressure events compared to nondepressions during ISM, 2016 and how it influences the radiative forcing at the surface and TOA. Given the large uncertainties in quantifying the influence of clouds on climate, the high-resolution observational characterization of the CVS and CRF performed in this study can be used to assess model skill at simulating physical and radiative properties of clouds and thereby gain a better understanding of the South Asian monsoon system. 


\section{Appendix A: Description of Applied Algorithm}

The algorithm by Zhang et al. (2010) was applied to determine cloud layers from within the RH vertical profiles obtained from the radiosonde soundings. The steps to detect clouds by identifying moist layers, as implemented in the present study, are as follows:

1. All $\mathrm{RH}$ values in the subzero range are converted to $\mathrm{RH}$ with respect to ice using the method suggested by Alduchov and Eskridge (1996).

2. To identify moist layers and detect clouds, vertical sonde profiles are checked against eight conditions, which are the following:

a. Going from the surface upward, the height at which $\mathrm{RH}$ value exceeds altitude-relevant $\mathrm{min}-\mathrm{RH}$ threshold is identified as the base of a moist layer.

b. The levels above this identified base are all considered within the moist layer, as long as these values remain greater than the corresponding $\mathrm{min}-\mathrm{RH}$.

c. The height at which the $\mathrm{RH}$ value falls below the corresponding $\min -\mathrm{RH}$, or where the $\mathrm{RH}$ value remains above the corresponding $\mathrm{min}-\mathrm{RH}$ but the end of the profile, is reached, is then considered the point at which the moist layer terminates, and is termed as the top of the moist layer.

d. Cases where the base of the moist layer is below $120 \mathrm{~m}$ from the surface and the thickness of the layer does not exceed $400 \mathrm{~m}$ are discarded.

e. If the $\mathrm{RH}$ values within the moist layer exceed the corresponding max- $\mathrm{RH}$ at the base of that layer, at least once, then this moist layer is confirmed as a cloud.

f. From the measurements of the ceilometer, it was found that the highest frequency of CBHs below $500 \mathrm{~m}$ was $\sim 200 \mathrm{~m}$, and hence, cloud layers are discarded if the top is found to be below this height.

g. Two consecutive layers are treated as a single cloud, provided the minimum $\mathrm{RH}$ in the thickness between these two layers is greater than the corresponding maximum inter-RH and if the distance between the top of the lower layer and the bottom of the upper layer does not exceed $300 \mathrm{~m}$.

h. Low (base $<2 \mathrm{~km}$ ), middle ( $2 \mathrm{~km}<$ base $<6 \mathrm{~km}$ ), and high (base $>6 \mathrm{~km}$ ) clouds with thicknesses less than $30.5 \mathrm{~m}, 61 \mathrm{~m}$, and $61 \mathrm{~m}$, respectively, were discarded.

This method thus provides a CVS containing information about the base heights, top heights, thicknesses of all clouds, and the number of layers present during each launch.

\section{Appendix B: Radiosonde Launches - Nominal Times}

The launch time of the radiosondes were not fixed for a certain time of day, as the launches could be carried out only after receiving prior permission from the local aviation authority, which would be available not earlier than $6 \mathrm{~h}$ prior to the launch time. However, the launches were carried out such that an interval of $4-5 \mathrm{~h}$ was maintained between the launches, as and when possible, at nominal times of $00,03,06,09,12,15,18$, and 21 UTC. For the actual schedule of launches, please refer Table B1 which lists all the launch times considered in this study.

\begin{tabular}{|c|c|c|c|c|c|c|c|c|}
\hline \multirow[b]{2}{*}{ Date } & \multicolumn{8}{|c|}{ Nominal launch time (UTC) } \\
\hline & 00 & 03 & 06 & 09 & 12 & 15 & 18 & 21 \\
\hline 5 July 2016 & & & & & $\checkmark$ & & $\checkmark$ & \\
\hline 6 July 2016 & $\checkmark$ & & $\checkmark$ & $\checkmark$ & $\checkmark$ & $\checkmark$ & $\checkmark$ & $\checkmark$ \\
\hline 7 July 2016 & $\checkmark$ & $\checkmark$ & $\checkmark \checkmark$ & & $\checkmark$ & $\checkmark$ & $\checkmark$ & $\checkmark$ \\
\hline 8 July 2016 & $\checkmark$ & $\checkmark$ & $\checkmark$ & $\checkmark$ & $\checkmark$ & $\checkmark$ & $\checkmark$ & $\checkmark$ \\
\hline 9 July 2016 & $\checkmark$ & $\checkmark$ & $\checkmark$ & $\checkmark$ & $\checkmark$ & $\checkmark$ & $\checkmark$ & $\checkmark$ \\
\hline 10 July 2016 & $\checkmark$ & $\checkmark$ & $\checkmark$ & $\checkmark$ & $\checkmark$ & $\checkmark$ & $\checkmark$ & $\checkmark$ \\
\hline 11 July 2016 & $\checkmark$ & $\checkmark$ & $\checkmark$ & $\checkmark$ & $\checkmark$ & $\checkmark$ & $\checkmark$ & $\checkmark$ \\
\hline 12 July 2016 & $\checkmark$ & $\checkmark$ & $\checkmark$ & $\checkmark$ & $\checkmark$ & $\checkmark$ & & \\
\hline 13 July 2016 & & $\checkmark$ & $\checkmark$ & & $\checkmark$ & & & \\
\hline 14 July 2016 & & $\checkmark$ & $\checkmark$ & $\checkmark$ & $\checkmark$ & $\checkmark$ & $\checkmark$ & \\
\hline 15 July 2016 & $\checkmark$ & $\checkmark$ & $\checkmark$ & $\checkmark$ & $\checkmark$ & & $\checkmark$ & \\
\hline
\end{tabular}




\begin{tabular}{|c|c|c|c|c|c|c|c|c|}
\hline \multirow[b]{2}{*}{ Date } & \multicolumn{8}{|c|}{ Nominal launch time (UTC) } \\
\hline & $\overline{00}$ & 03 & 06 & 09 & 12 & 15 & 18 & 21 \\
\hline 16 July 2016 & $\checkmark$ & $\checkmark$ & $\checkmark$ & $\checkmark$ & $\checkmark$ & & $\checkmark$ & \\
\hline 17 July 2016 & $\checkmark$ & $\checkmark$ & & $\checkmark$ & $\checkmark$ & & $\checkmark$ & \\
\hline 18 July 2016 & $\checkmark$ & & $\checkmark \checkmark$ & & $\checkmark$ & & $\checkmark \checkmark$ & \\
\hline 19 July 2016 & $\checkmark$ & $\checkmark$ & $\checkmark$ & & $\checkmark$ & & $\checkmark$ & \\
\hline 20 July 2016 & $\checkmark$ & $\checkmark$ & $\checkmark$ & $\checkmark$ & $\checkmark$ & & $\checkmark$ & \\
\hline 21 July 2016 & $\checkmark$ & $\checkmark$ & $\checkmark$ & & $\checkmark$ & & $\checkmark$ & \\
\hline 22 July 2016 & $\checkmark$ & & $\checkmark$ & $\checkmark$ & $\checkmark$ & & $\checkmark$ & \\
\hline 23 July 2016 & $\checkmark$ & & $\checkmark$ & & $\checkmark$ & & $\checkmark$ & \\
\hline 24 July 2016 & $\checkmark$ & & $\checkmark$ & $\checkmark$ & $\checkmark$ & & $\checkmark$ & \\
\hline 25 July 2016 & $\checkmark$ & & $\checkmark$ & & $\checkmark$ & & $\checkmark$ & \\
\hline 26 July 2016 & $\checkmark$ & & $\checkmark$ & & $\checkmark$ & & $\checkmark$ & \\
\hline 27 July 2016 & $\checkmark$ & & $\checkmark$ & $\checkmark \checkmark$ & $\checkmark$ & $\checkmark$ & $\checkmark$ & $\checkmark$ \\
\hline 28 July 2016 & $\checkmark$ & $\checkmark \checkmark$ & & $\checkmark \checkmark$ & & & & \\
\hline
\end{tabular}

Note. The tick marks indicate a launch, while the double tick means that one balloon was launched shortly after another, after an obvious failure of the balloon or communication with the sensor.

\section{Acknowledgments}

The authors gratefully acknowledge the financial support given by the Earth System Science Organization, Ministry of Earth Sciences, Government of India (grant MM/NERC-MoES-03/2014/002) under the INCOMPASS campaign and the Monsoon Mission. The INCOMPASS field campaign and A. G. Turner are supported in the UK by the NERC project NE/L01386X/1; this project also supported the purchase of radiosondes. The radiosonde receiving station was made available by the Department of Meteorology, University of Reading. ERA-Interim data were provided courtesy of ECMWF. CERES and MODIS data were obtained from the NASA Langley Research Center Atmospheric Science Data Center. All radiosonde data and surface radiation measurement data from flux tower at IITK can be downloaded from the INCOMPASS data set at CEDA (http://catalogue.ceda.ac.uk/uuid/ 2a31be48842149718c06b18f38fa9f56), with permission from the authors. In situ ground measurements of rainfall at the ITTK site are available at http://www.weather-risk.com. Request for data access of the same can be made to the authors (at snt@iitk.ac.in). The following people had helped during the radiosonde launches: Mithun Krishnan, Varunesh Chandra, Amit Misra, Jennifer Fletcher, Kieran Hunt, and Lucy Recchia. The authors also wish to acknowledge the help of Peter Willetts and Victoria Smith in setting up the ceilometer at IITK.

\section{References}

Air Weather Service (1979). The use of the skew $T, \log P$ diagram in analysis and forecasting (Tech. Rep.) Scott AFB, IL: Air Weather Service. Alduchov, O. A., \& Eskridge, R. E. (1996). Improved magnus form approximation of saturation vapor pressure. Journal of Applied Meteorology, 35(4), 601-609. https://doi.org/10.1175/1520-0450(1996)035<0601:IMFAOS>2.0.CO;2

Allan, R. P. (2011). Combining satellite data and models to estimate cloud radiative effect at the surface and in the atmosphere. Meteorological Applications, 18(3), 324-333. https://doi.org/10.1002/met.285

Barnes, G. M., Zipser, E. J., Jorgensen, D., \& Marks, F. (1983). Mesoscale and convective structure of a Hurricane Rainband. Journal of the Atmospheric Sciences, 40(9), 2125-2137. https://doi.org/10.1175/1520-0469(1983)040<2125:MACSOA > 2.0.CO;2

Bony, S., Stevens, B., Coppin, D., Becker, T., Reed, K. A., Voigt, A., \& Medeiros, B. (2016). Thermodynamic control of anvil cloud amount. Proceedings of the National Academy of Sciences, 113(32), 8927-8932. https://doi.org/10.1073/pnas.1601472113

Chernykh, I. V., \& Eskridge, R. E. (1996). Determination of cloud amount and level from radiosonde soundings. Journal of Applied Meteorology, 35(8), 1362-1369.

Costa-Surós, M., Calbó, J., González, J. A., \& Long, C. N. (2014). Comparing the cloud vertical structure derived from several methods based on radiosonde profiles and ground-based remote sensing measurements. Atmospheric Measurement Techniques, 7, 2757-2773. https://doi.org/www.atmos-meas-tech.net/7/2757/2014/

Dacre, H. F., Hawcroft, M. K., Stringer, M. A., \& Hodges, K. I. (2012). An extratropical cyclone atlas a tool for illustrating cyclone structure and evolution characteristics. Bulletin of the American Meteorological Society, 93(10), 1497-1502. https://doi.org/10.1175/BAMS-D-11-00164.1

Dee, D. P., Uppala, S. M., Simmons, A. J., Berrisford, P., Poli, P., Kobayashi, S., ... Vitart, F. (2011). The ERA-Interim reanalysis: Configuration and performance of the data assimilation system. Quarterly Journal of the Royal Meteorological Society, 137(656), 553-597.

Dmitrieva-Arrago, L. R., \& Shatunova, M. V. (1999). The approximate method of the cloud boundaries definition and its vertical distribution restoration. Research Activities in Atmospheric and Oceanic Modeling, 942, 4.5-46.

Eastman, R., \& Warren, S. G. (2013). A 39-yr survey of cloud changes from land stations worldwide 1971-2009: Long-term trends, relation to aerosols, and expansion of the tropical belt. Journal of Climate, 26(4), 1286-1303. https://doi.org/10.1175/JCLI-D-12-00280.1

Gadgil, S. (2003). The Indian monsoon and its variability. Annual Review of Earth and Planetary Sciences, 31(1), $429-467$. https://doi.org/10.1146/annurev.earth.31.100901.141251

Hartmann, D. L., Ramanathan, V., Berroir, A., \& Hunt, G. E. (1986). Earth radiation budget data and climate research. Reviews of Geophysics, 24(2), 439-468.

Hence, D. A., \& Houze, R. A. (2008). Kinematic structure of convective-scale elements in the rainbands of Hurricanes Katrina and Rita (2005). Journal of Geophysical Research, 113, D15108. https://doi.org/10.1029/2007JD009429

Hunt, G. E., Ramanathan, V., \& Chervin, R. M. (1980). On the role of clouds in the general circulation of the atmosphere. Quarterly Journal of the Royal Meteorological Society, 106(447), 213-215. https://doi.org/10.1002/qj.49710644714

Hunt, K. M. R., \& Parker, D. J. (2016). The movement of Indian monsoon depressions by interaction with image vortices near the Himalayan wall. Quarterly Journal of the Royal Meteorological Society, 142(698), 2224-2229. https://doi.org/10.1002/qj.2812

Hunt, K. M. R., \& Turner, A. G. (2017). The effect of horizontal resolution on Indian monsoon depressions in the Met Office NWP model. Quarterly Journal of the Royal Meteorological Society, 143(705), 1756-1771. https://doi.org/10.1002/qj.3030

Hunt, K. M. R., Turner, A. G., \& Parker, D. E. (2016). The spatiotemporal structure of precipitation in Indian monsoon depressions. Quarterly Journal of the Royal Meteorological Society, 142(701), 3195-3210. https://doi.org/10.1002/qj.2901

Hunt, K. M. R., Turner, A. G., Inness, P. M., Parker, D. E., \& Levine, R. C. (2016). On the structure and dynamics of Indian monsoon depressions. Monthly Weather Review, 144(9), 3391-3416. https://doi.org/10.1175/MWR-D-15-0138.1

Hurley, J. V., \& Boos, W. R. (2015). A global climatology of monsoon low-pressure systems. Quarterly Journal of the Royal Meteorological Society, 141(689), 1049-1064. https://doi.org/10.1002/qj.2447

Jauhiainen, H., Survo, P., Lehtinen, R., \& Lentonen, J. (2014). Radiosonde Rs41 and Rs92 key differences and comparison test results in different locations and climates. In Teco-2014, WMO technical conference on meteorological and environmental in-struments and methods of observations. Saint Petersburg, Russian Federation. 
Jensen, M. P., Holdridge, D., Survo, P., Lehtinen, R., \& Baxter, S. (2015). Comparison of Vaisala radiosondes RS41 and RS92 at the ARM Southern Great Plains site. Atmospheric Measurement Techniques, 9, 3115-3129. https://doi.org/10.5194/amtd-8-11323-2015

Kiehl, J. T. (1994). On the observed near cancellation between longwave and shortwave cloud forcing in tropical regions. Journal of Climate, 7, 559-565. https://doi.org/10.1175/1520-0442(1994)007<0559:OTONCB > 2.0.CO;2

Krishnamurti, T. N., Thomas, A., Simon, A., \& Kumar, V. (2010). Desert air incursions, an overlooked aspect, for the dry spells of the Indian summer monsoon. Journal of the Atmospheric Sciences, 67, 3423-3441.

Liang, X.-Z., \& Wang, W.-C. (1997). Cloud overlap effects on general circulation model climate simulations. Journal of Geophysical Research, 102(D10), 11,039-11,047. https://doi.org/10.1029/97JD00630

Lopez, M. A., Hartmann, D. L., Blossey, P. N., Wood, R., Bretherton, C. S., \& Kubar, T. L. (2008). A test of the simulation of tropical convective cloudiness by a cloud-resolving model. Journal of Climate, 22, 2834-2849. https://doi.org/10.1175/2008JCLI2272.1

Minnis, P., Yi, Y., Huang, J., \& Ayers, K. (2005). Relationships between radiosonde and RUC-2 meteorological conditions and cloud occurrence determined from ARM data. Journal of Geophysical Research, 110, D23204. https://doi.org/10.1029/2005JD006005

Patil, N. G., Tiwary, P., Bhattacharyya, T., Chandran, P., Sarkar, D., Pal, D. K., ... Thakre, S. (2014). Natural resources of the Indo-Gangetic Plains: A land-use planning perspective. Current Science, 107(9), 1537-1549.

Patil, S. D., \& Yadav, R. K. (2005). Large-scale changes in the cloud radiative forcing over the Indian region. Atmospheric Environment, 39(26), 4609-4618. https://doi.org/10.1016/j.atmosenv.2005.03.051

Poore, K. D., Wang, J., \& Rossow, W. B. (1995). Cloud layer thicknesses from a combination of surface and upper-air observations. Journal of Climate, 8, 550-568.

Rajeevan, M., \& Srinivasan, Jayes (2000). Net cloud radiative forcing at the top of the atmosphere in the Asian monsoon region. Journal of Climate, 13(3), 650-657. https://doi.org/10.1175/1520-0442(2000)013<0650:NCRFAT>2.0.CO;2

Rajeevan, M., Rohini, P., Niranjan Kumar, K., Srinivasan, J., \& Unnikrishnan, C. K. (2013). A study of vertical cloud structure of the Indian summer monsoon using CloudSat data. Climate Dynamics, 40(3-4), 637-650. https://doi.org/10.1007/s00382-012-1374-4

Ramanathan, V., Cess, R. D., Harrison, E. F., Minnis, P., Barkstrom, B. R., Ahmad, E., \& Hartmann, D. (1989). Cloud-radiative forcing and climate: Results from the Earth radiation budget experiment. Science, 243(4887), 57-63. https://doi.org/10.1126/science.243.4887.57

Ravi Kiran, V., Rajeevan, M., Gadhavi, H., Vijaya Bhaskara Rao, S., \& Jayaraman, A. (2015). Role of vertical structure of cloud microphysical properties on cloud radiative forcing over the Asian monsoon region. Climate Dynamics, 45(11-12), 3331-3345. https://doi.org/10.1007/s00382-015-2542-0

Sarangi, C., Tripathi, S. N., Tripathi, S., \& Barth, M. C. (2015). Aerosol-cloud associations over Gangetic Basin during a typical monsoon depression event using WRF-Chem simulation. Journal of Geophysical Research: Atmospheres, 120, 10,974-10,995. https://doi.org/10.1002/2015JD023634

Sarangi, C., Tripathi, S. N., Kanawade, V. P., Koren, I., \& Sivanand Pai, D. (2017). Investigation of the aerosol-cloud-rainfall association over the Indian summer monsoon region. Atmospheric Chemistry and Physics, 17(8), 5185-5204. https://doi.org/10.5194/acp-17-5185-2017

Sathiyamoorthy, V., Pal, P. K., \& Joshi, P. C. (2004). Influence of the upper-tropospheric wind shear upon cloud radiative forcing in the Asian monsoon region. Journal of Climate, 17, 2725-2735.

Saud, T., Dey, S., Das, S., \& Dutta, S. (2016). A satellite-based 13-year climatology of net cloud radiative forcing over the Indian monsoon region. Atmospheric Research, 182, 76-86. https://doi.org/10.1016/j.atmosres.2016.07.017

Sikka, D. R. (1977). Some aspects of the life history, structure and movement of monsoon depressions. Pure and Applied Geophysics PAGEOPH, 115(5-6), $1501-1529$. https://doi.org/10.1007/BF00874421

Slingo, A., \& Slingo, J. M. (1988). The response of a general circulation model to cloud longwave radiative forcing. I: Introduction and initial experiments. Quarterly Journal of the Royal Meteorological Society, 114(482), 1027-1062. https://doi.org/10.1002/qj.49711448209

Stephens, G. (1978). Radiation profiles in extended water cloud. I: Theory. Journal of the Atmospheric Sciences, 35, $2111-2122$.

Stephens, G. L. (2005). Cloud feedbacks in the climate system: A critical review. Journal of Climate, 18(2), 237-273. https://doi.org/10.1175/JCLI-3243.1

Stephens, G. L., \& Webster, P. J. (1979). Sensitivity of radiative forcing to variable cloud and moisture. Journal of the Atmospheric Sciences, 36 , $1542-1556$.

Stephens, G. L., \& Webster, P. J. (1984). Cloud decoupling of the surface and planetary radiative budgets. Journal of the Atmospheric Sciences, $41(4), 681-686$.

Su, W., Bodas-Salcedo, A., Xu, K. M., \& Charlock, T. P. (2010). Comparison of the tropical radiative flux and cloud radiative effect profiles in a climate model with Clouds and the Earth's Radiant Energy System (CERES) data. Journal of Geophysical Research, 115, D01105. https://doi.org/10.1029/2009JD012490

Thampi, B. V., \& Roca, R. (2014). Investigation of negative cloud radiative forcing over the Indian subcontinent and adjacent oceans during the summer monsoon season. Atmospheric Chemistry and Physics, 14(13), 6739-6758. https://doi.org/10.5194/acp-14-6739-2014

Turner, A., Bhat, G., Evans, J., Madan, R., Marsham, J., Martin, G., ... Tripathi, S. (2017). The INCOMPASS project field and modelling campaign: Interaction of convective organization and monsoon precipitation, atmosphere, surface and sea. In 19th EGU General Assembly, EGU2017, proceedings from the conference held 23-28 April, 2017 in Vienna, Austria. (17788 p.).

Wang, J., \& Rossow, W. B. (1995). Determination of cloud vertical structure from upper air observations. Journal of Applied Meteorology, 34 , $2243-2258$.

Wang, J., \& Rossow, W. B. (1998). Effects of cloud vertical structure on atmospheric circulation in the GISS GCM. Journal of Climate, 11(11), 3010-3029. https://doi.org/10.1175/1520-0442(1998)011<3010:EOCVSO > 2.0.CO;2

Wang, J., Rossow, W. B., Uttal, T., \& Rozendaal, M. (1999). Variability of cloud vertical structure during ASTEX observed from a combination of rawinsonde, radar, ceilometer, and satellite. Monthly Weather Review, 127, 2484-2502.

Wang, J., Rossow, W. B., \& Zhang, Y. (2000). Cloud vertical structure and its variations from a 20-year global rawinsonde dataset. Journal of Climate, 13, $3041-3056$.

Wang, W. C., Gong, W., Kau, W. S., Chen, C. T., Hsu, H. H., \& Tu, C. H. (2004). Characteristics of cloud radiation forcing over East China. Journal of Climate, 17(4), 845-853.

Wielicki, B. A., Barkstrom, B. R., Harrison, E. F., Lee, R. B., Smith, G. L., \& Cooper, J. E. (1996). Clouds and the Earth's Radiant Energy System (CERES): An Earth observing system experiment. Bulletin of the American Meteorological Society, $77(5), 853$. https://doi.org/10.1175/1520-0477(1996)077<0853:CATERE >2.0.CO;2

Zhang, J., Chen, H., Li, Z., Fan, X., Peng, L., Yu, Y., \& Cribb, M. (2010). Analysis of cloud layer structure in Shouxian, China using RS92 radiosonde aided by $95 \mathrm{GHz}$ cloud radar. Journal of Geophysical Research, 115, D00K30. https://doi.org/10.1029/2010JD014030

Zhang, J., Li, Z., Chen, H., Yoo, H., \& Cribb, M. (2014). Cloud vertical distribution from radiosonde, remote sensing, and model simulations. Climate Dynamics, 43, 1129-1140. https://doi.org/10.1007/s00382-014-2142-4 